Article

\title{
Synthesis and Cytotoxicity Evaluation of DOTA-Conjugates of Ursolic Acid
}

\author{
Michael Kahnt ${ }^{1}\left(\mathbb{D}\right.$, Sophie Hoenke ${ }^{1}$, Lucie Fischer ${ }^{1}$, Ahmed Al-Harrasi ${ }^{2}$ and René Csuk ${ }^{1, *(1)}$ \\ 1 Organic Chemistry, Martin-Luther-University Halle-Wittenberg, Kurt-Mothes-Str. 2, D-06120 Halle (Saale), \\ Germany; michael.kahnt@chemie.uni-halle.de (M.K.); sophie.hoenke@chemie.uni-halle.de (S.H.); \\ lucie.fischer2018@gmx.de (L.F.) \\ 2 Natural and Medical Sciences Research Center, University of Nizwa, PO Box 33, Birkat Al-Mauz, \\ Nizwa 616,Oman; aharrasi@unizwa.edu.om \\ * Correspondence: rene.csuk@chemie.uni-halle.de; Tel.: +49-345-55-25660
}

Academic Editor: Kyoko Nakagawa-Goto

Received: 12 May 2019; Accepted: 14 June 2019; Published: 17 June 2019

check for updates

\begin{abstract}
In this study, we report the synthesis of several amine-spacered conjugates of ursolic acid (UA) and 1,4,7,10-tetraazacyclododecane-1,4,7,10-tetraacetic acid (DOTA). Thus, a total of 11 UA-DOTA conjugates were prepared holding various oligo-methylene diamine spacers as well as different substituents at the acetate units of DOTA including tert-butyl, benzyl, and allyl esters. Furthermore, three synthetic approaches were compared for the ethylenediamine-spacered conjugate 29 regarding reaction steps, yields, and precursor availability. The prepared conjugates were investigated regarding cytotoxicity using SRB assays and a set of human tumor cell lines. The highest cytotoxicity was observed for piperazinyl spacered compound 22. Thereby, $\mathrm{EC}_{50}$ values of $1.5 \mu \mathrm{M}$ (for A375 melanoma) and $1.7 \mu \mathrm{M}$ (for A2780 ovarian carcinoma) were determined. Conjugates 22 and 24 were selected for further cytotoxicity investigations including fluorescence microscopy, annexin $\mathrm{V}$ assays and cell cycle analysis.
\end{abstract}

Keywords: ursolic acid; DOTA; triterpenoids; cytotoxicity

\section{Introduction}

Despite all medical advances in tumor therapy, cancer is still one of the most prevalent diseases worldwide, with 9.6 million cancer-related deaths counted in 2018 [1]. The research of novel therapeutic approaches and potent chemotherapeutic agents are important contributions in the battle against cancer. However, diagnosis is a prerequisite for successful treatment since an early detection of cancer cells can often significantly reduce the pathogenicity of a tumor and increase the healing rate. One molecule, which made significant impact on the field of diagnostic imaging in the past decades, is the EDTA-related macrocyclic chelator 1,4,7,10-tetraazacyclododecane-1,4,7,10-tetraacetic acid (DOTA, Figure 1) [2,3].

DOTA-derivatives and complexes thereof are widely used for molecular imaging, especially for the medical diagnosis of cancer [2,3]. By variation of the coordinated metal ion or substituents, they are applicable for a number of imaging techniques, such as magnetic resonance imaging (MRI) [2-4], positron emission tomography (PET) $[2,3,5,6]$ and single photon emission computed tomography (SPECT) $[2,3,7]$. Because of this versatility, a crossover application of DOTA-derivatives as multimodal contrast agents for combined imaging modalities such as PET/MRI or PET/CT is possible and has already been described in the literature [2,3].

Although DOTA and derivatives thereof have a wide range of uses in diagnostic imaging, there are virtually no references for applications in the therapy of cancer. Therefore, we decided to prepare possible cytotoxic DOTA-derivatives by linkage with an ursolic acid backbone. Ursolic 
acid (UA, Figure 1) is a natural occurring triterpenoic acid with promising pharmacological properties, being widely distributed in various plants and fruits, such as rosemary [8], sage [8], oleander [9], and apples [10,11]. A wide range of biological activities, including antidiabetic, anti-inflammatory, antibacterial, and anticancer effects have been credited to UA and structurally-related derivatives [12-14]. Many structural modifications have been described in the literature starting from ursolic acid with various impacts on cytotoxic properties [12,15-18]. Structure activity investigations concerning modifications at C-3 of UA revealed the presence of an acetyloxy group to be beneficial for obtaining high anti-tumor activity [18]. Furthermore, it has been shown that the modification of C-28 with a piperazine moiety had a positive influence on the cytotoxic properties of ursolic acid $[19,20]$. Previously, we also have shown oligo-methylene diamine derived carboxamides of ursolic acid to be of high cytotoxicity [21]. Keeping these structure activity relationships in mind, we considered 3-acetyloxy protected and C-28 modified UA derivatives a convenient starting point for the preparation of cytotoxic oligo-methylene diamine spacered DOTA conjugates.

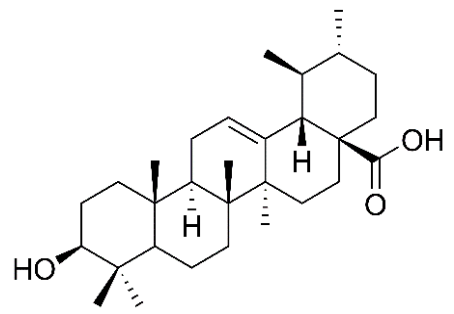

UA

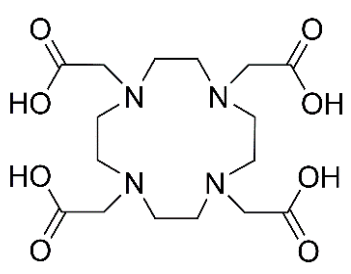

DOTA

Figure 1. Structures of ursolic acid (UA) and 1,4,7,10-tetraazacyclododecane-1,4,7,10-tetraacetic acid (DOTA).

\section{Results and Discussion}

The synthesis of UA-DOTA conjugates started with the structural modification of cyclen (2) as illustrated in Scheme 1. Treatment of 2 with 3 equiv. of sodium bicarbonate and 3 equiv. of the respective bromoacetic ester (3-5) in dry acetonitrile yielded triple substituted cyclen derivatives 6-8, being ready to be coupled with ursolic acid. We decided to use tert-butyl, benzyl and allyl esters as protecting groups. Benzyl, as well as tert-butyl bromoacetate, were bought from commercial suppliers. Allyl bromoacetate was prepared from allylic alcohol and bromoacetyl bromide.

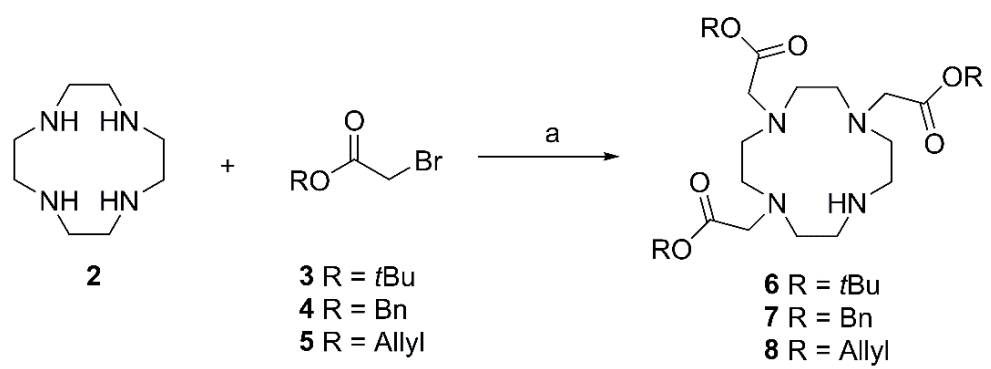

Scheme 1. Synthesis of DOTA precursors 6-8: (a) $\mathrm{NaHCO}_{3}, \mathrm{MeCN}, 25^{\circ} \mathrm{C}, 48 \mathrm{~h}$, yield: $50 \%$ (6), 68\% (7), $63 \%(8)$.

Ursolic acid has also been modified before coupling with the DOTA precursors (Scheme 2). Derivatization started with the attachment of a spacer moiety using oxalyl chloride and 1-(2-aminoethyl)piperazine in dry dichloromethane affording compound $\mathbf{1 0}$. The terminal amino moiety was further substituted with chloroacetyl chloride in dry dichloromethane to furnish the ursolic acid precursor $\mathbf{1 1}$ in excellent yield. Linkage of both precursors was performed in dry acetonitrile in the presence of potassium carbonate and potassium iodide yielding UA-DOTA conjugates 12-14. Allylic esters of the acetate groups were removed by treating compound 14 with $\left[\left(\mathrm{PPh}_{3}\right)_{4} \mathrm{Pd}\right]$, 
triphenylphosphane and pyrrolidine in acetonitrile at $25^{\circ} \mathrm{C}$ for 3 days; this procedure gave 15 in almost quantitative yield. Purification of $\mathbf{1 5}$ was performed by reversed phase chromatography using $\mathrm{MeOH} / \mathrm{MeCN} / \mathrm{TFA}$ as eluent since the compound was difficult to eluate from normal silica phases. Furthermore, a synthetic approach for $\mathbf{1 5}$ starting from either $\mathbf{1 2}$ or $\mathbf{1 3}$ failed. Hydrogenation of 13 employing palladium catalysis retained the benzyl esters, and the deprotection of tert-butyl esters (as in compound 12) using TFA/DCM resulted in a partial degradation of the triterpenoic backbone.

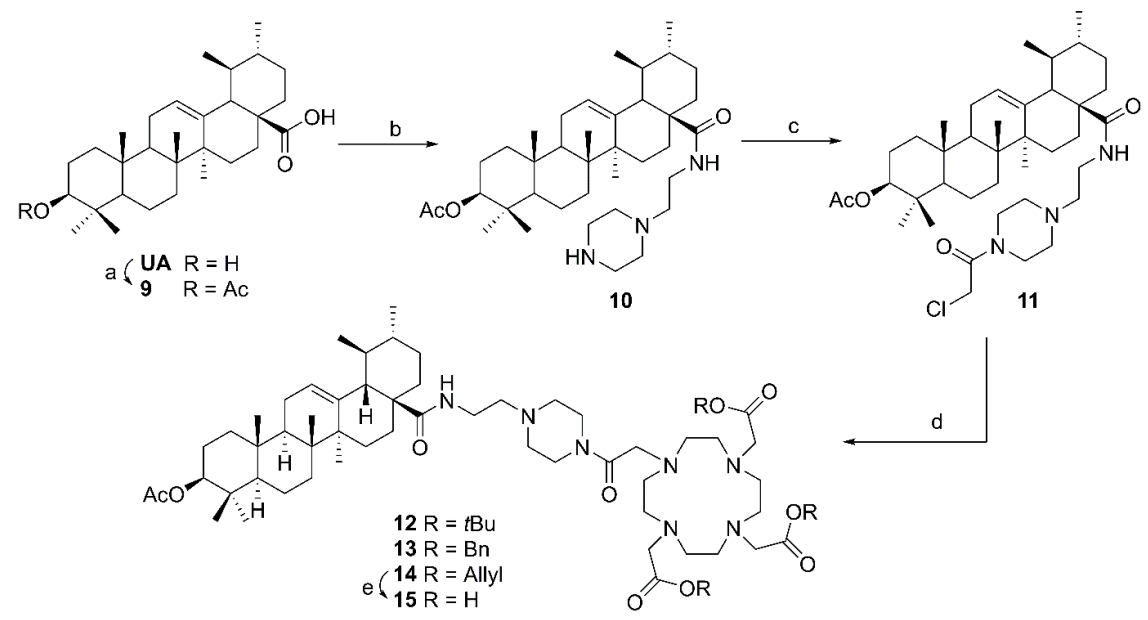

Scheme 2. Synthesis of ursolic acid chelator conjugates 12-15: (a) $\mathrm{Ac}_{2} \mathrm{O}, \mathrm{CH}_{2} \mathrm{Cl}_{2}, \mathrm{NEt}_{3}, 25^{\circ} \mathrm{C}, 2$ days, $82 \%$; (b) oxalyl chloride, $\mathrm{CH}_{2} \mathrm{Cl}_{2}$, DMF, $0-25^{\circ} \mathrm{C}, 1 \mathrm{~h}$, then 1-(2-Aminoethyl)piperazine, $\mathrm{CH}_{2} \mathrm{Cl}_{2}, 25^{\circ} \mathrm{C}$, 2 h, yield: $82 \%$; (c) chloroacetyl chloride, $\mathrm{CH}_{2} \mathrm{Cl}_{2}, \mathrm{NEt}_{3}, 25{ }^{\circ} \mathrm{C}, 30 \mathrm{~min}$, yield: $91 \%$; (d) $\mathrm{K}_{2} \mathrm{CO}_{3}, \mathrm{KI}$, 6 (for 12) or 7 (for 13) or 8 (for 14), MeCN, $25^{\circ} \mathrm{C}, 48 \mathrm{~h}$, yield: $54 \%$ (12), 82\% (13), and 80\% (14); (e) $\left[\left(\mathrm{PPh}_{3}\right)_{4} \mathrm{Pd}\right], \mathrm{PPh}_{3}$, pyrrolidine, $\mathrm{MeCN}, 25^{\circ} \mathrm{C}, 3$ days, yield: $96 \%$.

The synthetic approach summarized in Scheme 2 can also be applied to various other spacer units. Thus, we decided to alter the amino component. Therefore, ursolic acid was treated with piperazine, ethylene diamine and 2,2'-oxybis(ethylamine), to furnish ursolic carboxamides 16-18 (Scheme 3), respectively. Chloroacetyl derivatives 19-21 and UA-DOTA conjugates 22-27 were prepared analogous to Scheme 2.

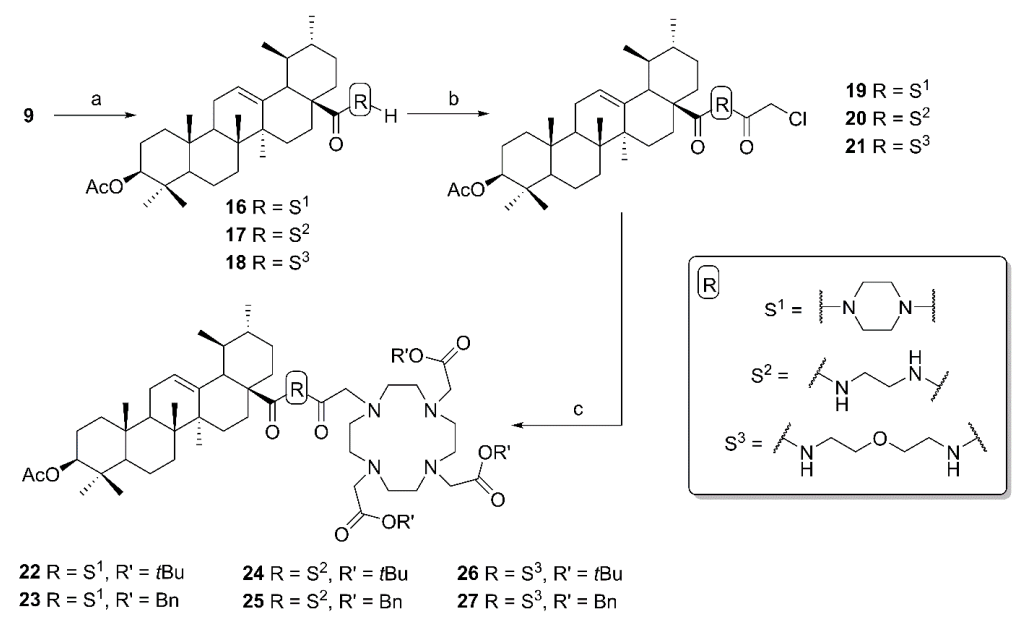

Scheme 3. Synthesis of ursolic acid DOTA conjugates 22-27: (a) oxalyl chloride, $\mathrm{CH}_{2} \mathrm{Cl}_{2}, \mathrm{DMF}, 0-25^{\circ} \mathrm{C}$, $1 \mathrm{~h}$, then amine, $\mathrm{CH}_{2} \mathrm{Cl}_{2}, 25^{\circ} \mathrm{C}, 2 \mathrm{~h}$, yield: 80\% (16 and 17), and 78\% (18); (b) chloroacetyl chloride, $\mathrm{CH}_{2} \mathrm{Cl}_{2}, \mathrm{NEt}_{3}, 25^{\circ} \mathrm{C}, 0.5-4 \mathrm{~h}$, yield: $94 \%$ (19), and 91\% (20 and 21); (c) $\mathrm{K}_{2} \mathrm{CO}_{3}, \mathrm{KI}, 6$ (for 22, 24 and 26) or 7 (for 23, 25 and 27), MeCN, $25^{\circ} \mathrm{C}$, 5 days, yield: 88\% (22), 72\% (23), 73\% (24), 75\% (25), 74\% (26), and $62 \%(27)$. 
Additionally, an alternative synthetic approach was established for the preparation of the ethylene diamine-spacered UA-DOTA conjugate 29 (Scheme 4). Therefore carboxamide 28 was prepared either by deacetylation of $\mathbf{1 7}$ or directly from UA by amidation with ethylene diamine using EDC and HOBt in dry DMF. In the next step, DOTA-tris(tert-butyl ester) (DOTA-3T) was activated by preparing its HOBt ester. Adding $\mathbf{2 8}$ to this freshly prepared ester furnished UA-DOTA conjugate 29. For comparison, compound 29 was also synthesized from 24 by removing the C-3 acetyloxy moiety. Due to the presence of an unprotected hydroxyl moiety at this position, compound 29 offers the possibility for a set of modifications and is therefore considered to be a good starting material for further modifications.

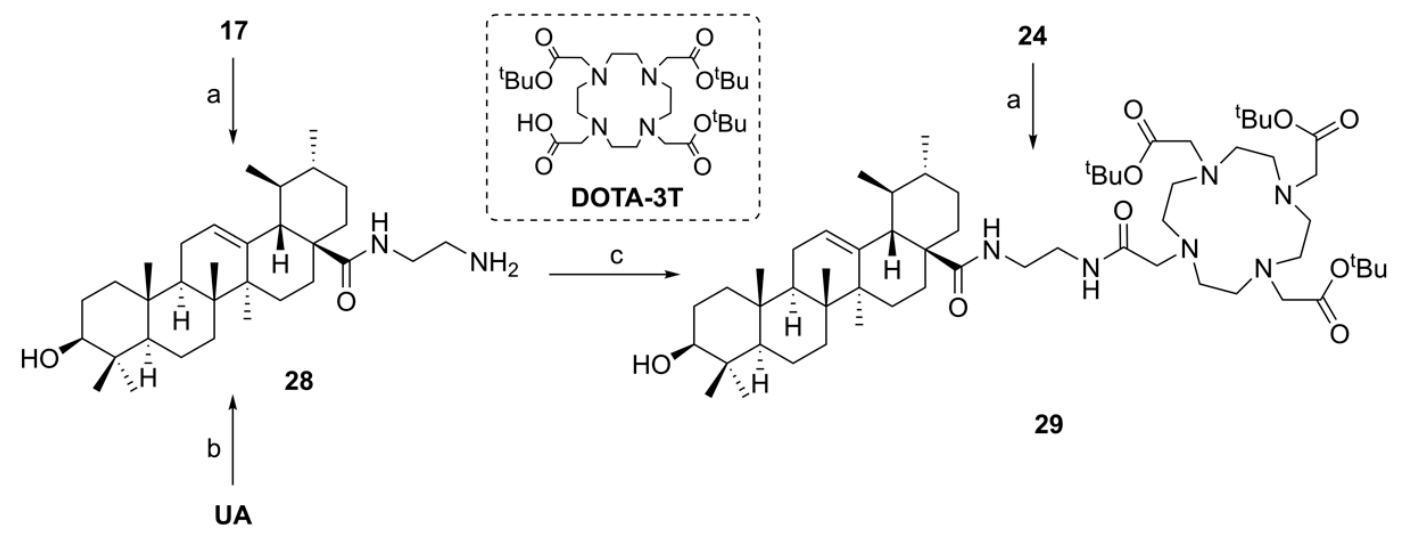

Scheme 4. Synthesis of ursolic acid derivative 29: (a) $\mathrm{KOH}, \mathrm{MeOH}, 25^{\circ} \mathrm{C}, 48 \mathrm{~h}$ (for 28) or $24 \mathrm{~h}$ (for 29), yield: $85 \%$ (28) or $86 \%$ (29); (b) ethylene diamine, $\mathrm{HOBt} \cdot \mathrm{H}_{2} \mathrm{O}, \mathrm{EDC} \cdot \mathrm{HCl}, \mathrm{DMF}, 25^{\circ} \mathrm{C}, 24 \mathrm{~h}$, yield: $46 \%$ (c) DOTA-3T, $\mathrm{HOBt} \cdot \mathrm{H}_{2} \mathrm{O}, \mathrm{EDC} \cdot \mathrm{HCl}, \mathrm{DMF}, 25^{\circ} \mathrm{C}, 5$ days, yield: $49 \%$.

Both synthetic approaches for the preparation of 29 (Figure 2) hold advantages but also some disadvantages. Although route A (5 steps) is significantly longer than B, but the former route gave the highest overall yield (44\%). Approach B is a rather short and quick way to synthesize 29 ( 2 steps only), but the overall yield ( $23 \%$ ) is barely half as high as in route A. Combining routes A and $\mathrm{B}$, as shown in approach $\mathrm{C}$ led to compound 29 in 4 steps with an overall yield of $32 \%$. A major difference between the approaches $\mathrm{A}$ and $\mathrm{B}$ is the availability and preparation of the DOTA precursors. Both, DOTA-tris(tert-butyl ester) and DO3A-tert-butyl ester (6) are available from commercial suppliers, with DOTA-3T being almost twice as expensive as $\mathbf{6}$. Most advantageous is the one-step synthesis of 6 starting from cylcen (2), since $\mathbf{2}$ is commercially available for a price, being almost tenfold lower than that of 6 .

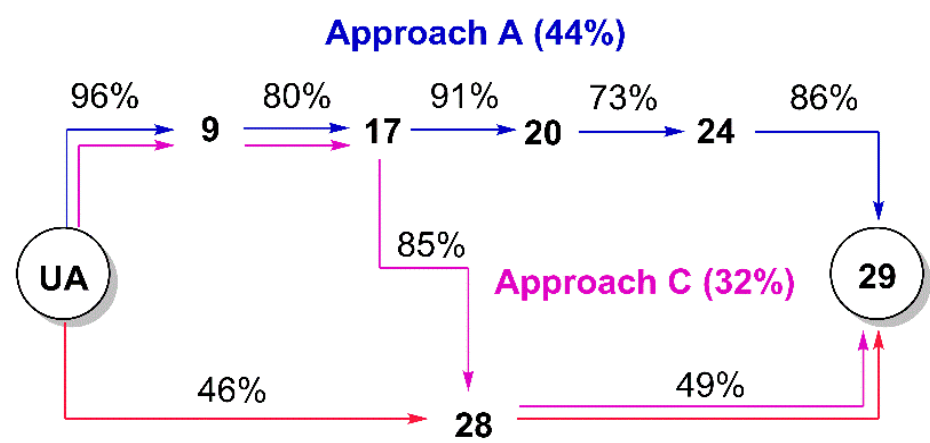

Approach B (23\%)

Figure 2. Comparison of synthetic routes A, B, and C for the preparation of UA-DOTA conjugate 29.

Due to cytotoxicity evaluation, the prepared UA-DOTA conjugates were screened in rhodamine B assays employing a series of human tumor cell lines and non-malignant mouse fibroblasts (NIH 3T3). Results of this investigation are summarized in Table 1. 
Table 1. Cytotoxicity of UA-DOTA conjugates $(\mathbf{1 2 - 1 5}, \mathbf{2 2 - 2 7 , 2 9 ) , ~ D O T A ~ p r e c u r s o r s ~}(\mathbf{6}, 7)$, ursolic acid (UA), and doxorubicin hydrochloride (DRC): $\mathrm{EC}_{50}$ values from SRB assays after $72 \mathrm{~h}$ of treatment are given in $\mu \mathrm{M}$ (n.d. not detected; n.s. not soluble); the values are averaged from three independent experiments each performed in triplicate; confidence interval $\mathrm{CI}=95 \%$.

\begin{tabular}{ccccccc}
\hline & A375 & A2780 & HT29 & MCF-7 & FaDu & NIH 3T3 \\
\hline UA & n.d. & $11.7 \pm 0.6$ & $10.6 \pm 0.7$ & $12.7 \pm 0.1$ & n.d. & $13.1 \pm 1.1$ \\
$\mathbf{6}$ & $12.4 \pm 2.7$ & $10.5 \pm 3.0$ & $8.7 \pm 2.7$ & $11.3 \pm 2.3$ & $9.5 \pm 0.9$ & $17.3 \pm 0.1$ \\
$\mathbf{7}$ & $4.7 \pm 0.3$ & $3.8 \pm 0.3$ & $2.0 \pm 0.2$ & $4.1 \pm 0.5$ & $3.9 \pm 0.7$ & $4.5 \pm 0.3$ \\
$\mathbf{1 3}$ & n.d. & $2.1 \pm 0.4$ & $4.0 \pm 0.4$ & $3.3 \pm 0.2$ & $6.0 \pm 0.1$ & $3.6 \pm 0.5$ \\
$\mathbf{1 5}$ & $>60$ & $>60$ & $>60$ & $>60$ & $>60$ & $>60$ \\
$\mathbf{2 2}$ & $1.5 \pm 0.4$ & $1.9 \pm 0.3$ & $5.7 \pm 0.5$ & $4.4 \pm 0.7$ & $3.7 \pm 0.6$ & $4.6 \pm 1.0$ \\
$\mathbf{2 4}$ & $2.0 \pm 0.1$ & $1.7 \pm 0.1$ & $2.3 \pm 0.3$ & $1.8 \pm 0.1$ & $2.0 \pm 0.2$ & $1.4 \pm 0.1$ \\
$\mathbf{2 9}$ & $2.0 \pm 0.3$ & $1.6 \pm 0.5$ & $1.7 \pm 0.4$ & n.d. & $2.9 \pm 0.4$ & $2.3 \pm 0.7$ \\
$\mathbf{1 2} \mathbf{1 4}, \mathbf{2 3}, \mathbf{2 5 - 2 7}$ & n.s. & n.s & n.s & n.s. & n.s. & n.s. \\
DRC & n.d. & $0.01 \pm 0.01$ & $0.9 \pm 0.2$ & $1.1 \pm 0.3$ & n.d. & $0.06 \pm 0.03$ \\
\hline
\end{tabular}

The DO3A-tert-butyl ester (6) showed moderate cytotoxicity as indicated by $\mathrm{EC}_{50}$ values between $10 \mu \mathrm{M}$ and $14 \mu \mathrm{M}$, while DO3A-benzyl ester (7) showed $\mathrm{EC}_{50}$ values lower than $5 \mu \mathrm{M}$. Unfortunately, most of the UA-DOTA conjugates were not soluble in solvents suitable for SRB assays. However, combining 7 with ursolic acid gave cytotoxic conjugate 13, showing $\mathrm{EC}_{50}$ values below $6 \mu \mathrm{M}$. Removal of ester units (as in 15) resulted in a complete loss of cytotoxicity ( $\mathrm{EC}_{50}>60 \mu \mathrm{M}$ for all tumor cells). Compounds 22 and 24, both holding tert-butyl esters but different spacer units were also highly cytotoxic. Piperazine-spacered conjugate 22 showed the highest cytotoxicity observed in this screening for $\mathrm{A} 375$ tumor cells $\left(\mathrm{EC}_{50}=1.5 \pm 0.4 \mu \mathrm{M}\right)$, while being quite selective, too (SI $(\mathrm{NIH} 3 \mathrm{~T} 3 / \mathrm{A} 375)=3.07$, Table 2). $\mathrm{EC}_{50}$ values of ethylenediamine-spacered conjugate 24 were below $2.5 \mu \mathrm{M}$ for all tumor cell lines. The highest cytotoxicity was observed for ovarian carcinoma (A2780, $\mathrm{EC}_{50}=1.7 \pm 0.1 \mu \mathrm{M}$ ). Removal of the acetyloxy moiety of $\mathbf{2 4}$ (as in $\mathbf{2 9}$ ) had almost no significant impact on cytotoxicity.

Table 2. Selectivity of selected UA-DOTA conjugates $(\mathbf{1 3}, \mathbf{2 2}, \mathbf{2 4}$, and 29), DOTA precursors $(\mathbf{6}, \mathbf{7})$, ursolic acid (UA) and doxorubicin hydrochloride (DRC): Selectivity index (SI) is defined as: $\mathrm{SI}=\mathrm{EC}_{50}$ (NIH 3T3)/EC 50 (tumor cell line).

\begin{tabular}{cccccc}
\hline & A375 & A2780 & HT29 & MCF-7 & FaDu \\
\hline UA & - & 1.12 & 1.24 & 1.03 & - \\
$\mathbf{6}$ & 1.40 & 1.65 & 1.99 & 1.53 & 1.82 \\
$\mathbf{7}$ & 0.96 & 1.18 & 2.25 & 1.10 & 1.15 \\
$\mathbf{1 3}$ & - & 1.71 & 0.90 & 1.09 & 0.60 \\
$\mathbf{2 2}$ & 3.07 & 2.42 & 0.81 & 1.05 & 1.24 \\
$\mathbf{2 4}$ & 0.70 & 0.82 & 0.61 & 0.78 & 0.70 \\
$\mathbf{2 9}$ & 1.15 & 1.44 & 1.35 & - & 0.79 \\
DRC & - & 6.00 & 0.07 & 0.05 & - \\
\hline
\end{tabular}

Because UA-DOTA conjugates $\mathbf{2 2}$ and $\mathbf{2 4}$ were the most active compounds of this study, these compounds were selected for further cytotoxicity investigations including fluorescence microscopy, annexin $\mathrm{V}$ assays, and cell cycle evaluation employing melanoma cells (A375). Microscopic images of A375 cells treated with compound 24 for $24 \mathrm{~h}$ showed vital cells (green staining) with some of them having ruptured cell membranes (Figure 3A, white arrows). Further indications of apoptosis have been detected employing flow cytometry and annexin V-FITC/PI staining. After $24 \mathrm{~h} 63 \%$ of the tumor cells treated with 24 were annexin V-FITC-positive, and 51.9\% of all cells having died by apoptosis. Additionally, the number of vital cells decreased in comparison to the control from $86.1 \%$ to $36.7 \%$ (Figure 3B). An extra investigation of the cell cycle showed a decreased number of cells in G1/G0, G2/M, as well as in S phase. Additionally, a large population of cells has been shifted into the subG1 region (Figure 3C). 
A
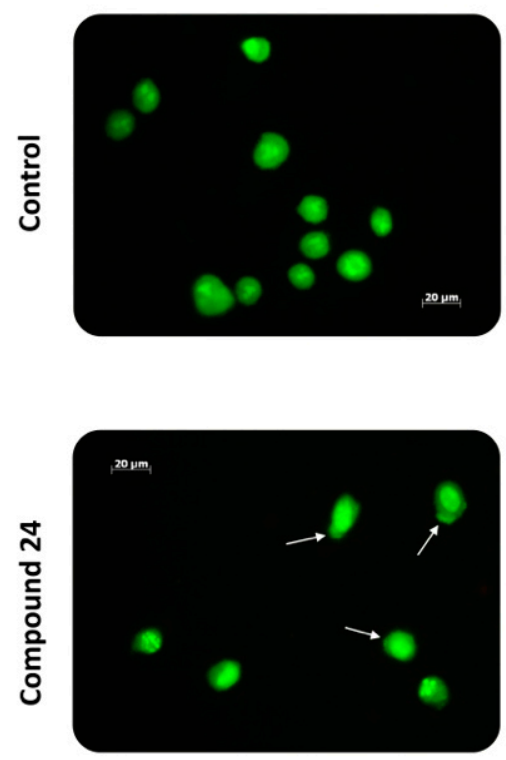

B
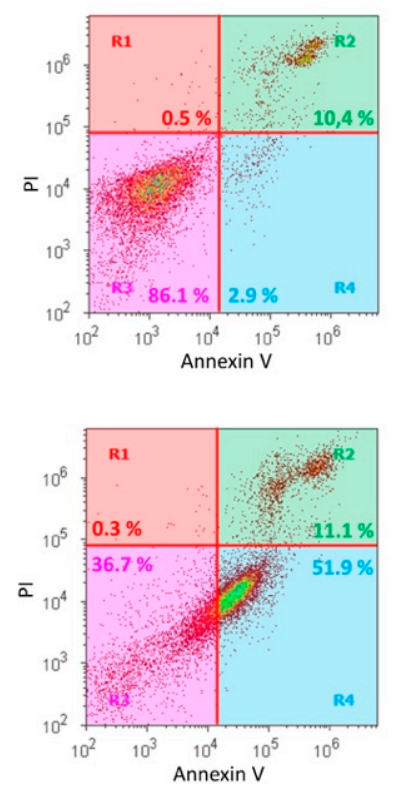

C
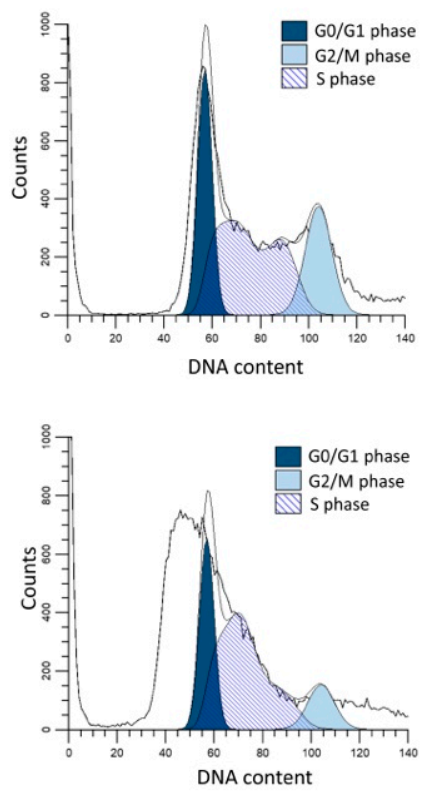

Figure 3. Extended cytotoxicity investigation after treatment of A375 cells with $24(4.0 \mu \mathrm{M})$ for $24 \mathrm{~h}$ : (A) Fluorescence microscopic images (scale bar $20 \mu \mathrm{m}$ ), AO and PI were used; (B) Annexin V-FITC/PI assay. Examples of density plots determined by flow cytometry (Attune ${ }^{\circledR}$ Cytometric Software v 1.2.5), R1: necrotic, R2: secondary necrotic/late stage apoptotic, R3: vital, R4: apoptotic; (C) Representative examples for cell cycle evaluation via ModFit LT 5.0.

Fluorescence microscopic images and density plots of A375 cells treated with 22 for 24 h showed no significant differences in comparison to the control (Supplementary material, Figure S1). Therefore, further investigations were performed with a prolonged incubation time of $48 \mathrm{~h}$. After treating A375 cells with compound 22 for $48 \mathrm{~h}$, subsequent fluorescence microscopic investigations using $\mathrm{AO} / \mathrm{PI}$ staining showed ruptures of the plasma membrane (Figure $4 \mathrm{~A}$, white arrows). Additionally, some necrotic/late stage apoptotic cells were observed, indicated by slightly orange stained nuclei (Figure $4 \mathrm{~A}$, orange arrow). The density plot of A375 cells treated with $\mathbf{2 2}$ for $48 \mathrm{~h}$ showed a decreased number of vital cells $(66.3 \%)$ compared to the control $(86.0 \%)$, while $32.9 \%$ of the cells were considered annexin V-FITC-positive. Nearly half of them (17.4\% of all cells) have died by apoptosis, and the remaining cells ( $15.5 \%$ of all cells) were secondary necrotic/late stage apoptotic (Figure 4 B). During extra investigations of the cell cycle, some differences compared to the control have been observed. Cells treated with 22 for 48 h showed a quite broad and flat DNA distribution. G1/G0, G2/M, and S phase were drastically reduced, while an increased population of cells with reduced DNA content has been observed in the subG1 region (Figure 4C). 
A
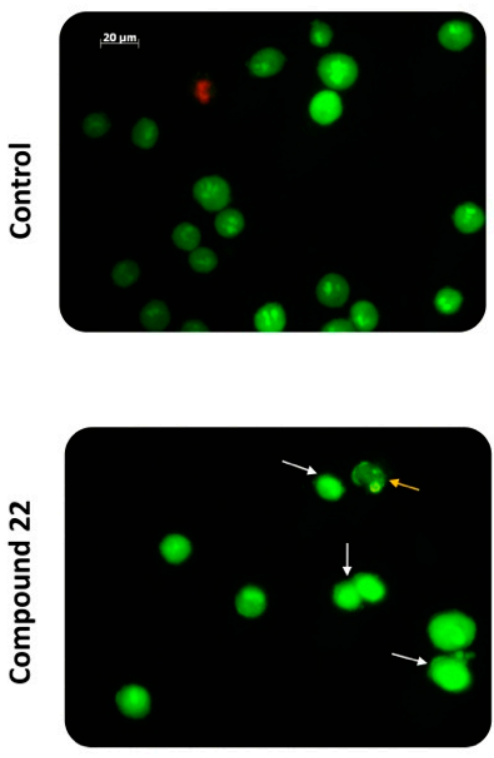

B
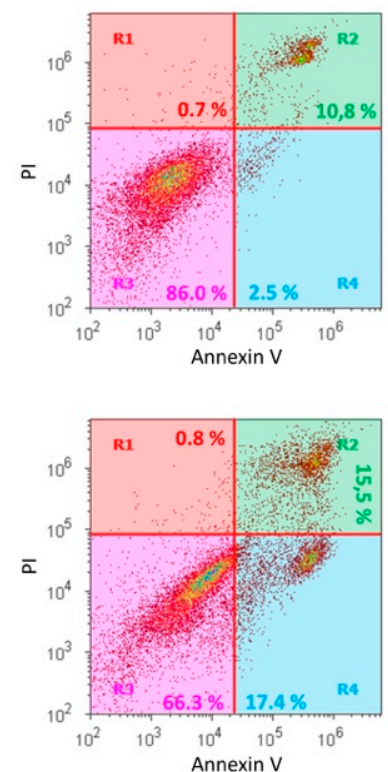

C
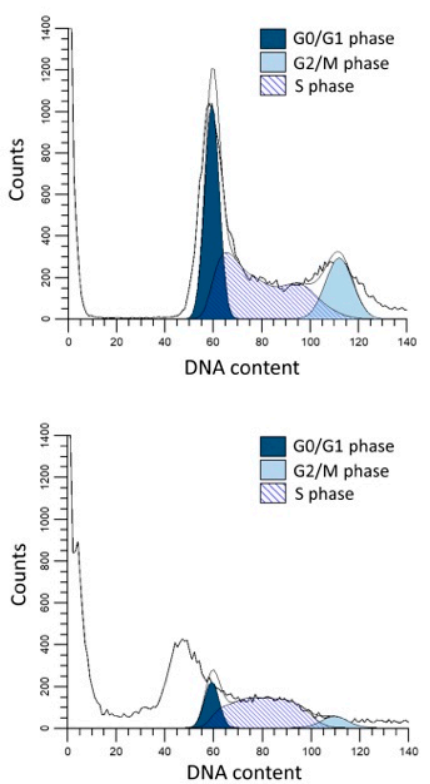

Figure 4. Extended cytotoxicity investigation after treatment of A375 cells with $22(3.0 \mu \mathrm{M})$ for 48 h: (A) Fluorescence microscopic images (scale bar $20 \mu \mathrm{m}$ ), AO and PI were used; (B) Annexin V-FITC/PI assay. Examples of density plots determined by flow cytometry (Attune ${ }^{\circledR}$ Cytometric Software vl 1.2.5), R1: necrotic, R2: secondary necrotic/late stage apoptotic, R3: vital, R4: apoptotic; (C) Representative examples for cell cycle evaluation via ModFit LT 5.0.

\section{Conclusions}

In this study, a series of overall 11 amine-spacered UA-DOTA conjugates have been prepared starting from the natural occurring triterpenoid ursolic acid (UA). We hereby report a synthetic approach to UA-DOTA conjugates, which is applicable for several amine spacers and other triterpenoic backbones, too. Additionally, we compared three synthetic approaches for the preparation of compound 29 in terms of yield, number of steps and precursor availability. This conjugate offers the possibility for further modifications at the $\mathrm{C}-3$ hydroxylic group, which is known to influence cytotoxicity. All of the prepared DOTA conjugates were screened in SRB assays showing some compounds to be of good cytotoxicity. $\mathrm{EC}_{50}$ values were determined to range from $17.3 \mu \mathrm{M}$ to $1.4 \mu \mathrm{M}$. The most active compound of this series was a piperazinyl spacered conjugate 22 showing low $\mathrm{EC}_{50}$ values such as $1.5 \pm 0.4 \mu \mathrm{M}$ for A375 tumor cells and $1.9 \pm 0.3 \mu \mathrm{M}$ for A2780 tumor cells, respectively, while showing good selectivity (SI (NIH 3T3(A375) = 3.07), too. Unfortunately, the selectivity of the other screened conjugates was quite low. Additional cytotoxicity investigations such as fluorescence microscopy, annexin $\mathrm{V}$ assays, and cell cycle analyses were performed employing the UA-DOTA conjugates 22 and $\mathbf{2 4}$ to gain information about their mode of action. The results of these extended biological testing indicate 24 to induce death of A375 cancer cells by apoptosis. These results hold some starting points for further studies. Conjugate 15 and structural related compounds (holding free carboxylic acids at the DOTA unit) are currently subjects of ongoing investigations regarding their ability to form complexes with metal ions or radioactive isotopes like ${ }^{68} \mathrm{Ga}$ to examine possible future uses as tracer or contrast agents in molecular imaging techniques, such as positron emission tomography (PET) [22].

\section{Materials and Methods}

\subsection{General}

NMR spectra were recorded using the Varian spectrometers Gemini 2000 or Unity 500 (Varian $\mathrm{GmbH}$, Darmstadt, Germany) $\delta$ given in ppm, $J$ in Hz; typical experiments: APT, H-H-COSY, 
HMBC, HSQC, NOESY), MS spectra were taken on a Finnigan MAT LCQ 7000 (ThermoFisher Scientific, Braunschweig, Germany) electrospray, voltage $4.1 \mathrm{kV}$, sheath gas nitrogen) instrument. The optical rotations were measured on a Perkin-Elmer polarimeter (Perkin Elmer LAS, Rodgau, Germany) or on a Jasco P-2000 polarimeter (Jasco Germany, Pfungstadt, Germany) at $20^{\circ} \mathrm{C}$; TLC was performed on NP or RP18 silica gel (Macherey-Nagel, detection with cerium molybdate or Dragendorff's reagent). Melting points are uncorrected (Leica hot stage microscope, or BUCHI melting point M-565), and elemental analyses were performed on a Foss-Heraeus Vario EL (CHNS, Elementar Analysensysteme GmbH, Langenselbold, Germany) unit. IR spectra were recorded on a Perkin Elmer FT-IR spectrometer Spectrum 1000 or on a Perkin-Elmer Spectrum Two (UATR Two Unit; both instruments from Perkin Elmer LAS, Rodgau, Germany). UV-VIS spectra were taken on a Perkin-Elmer Lambda 14 spectrometer or on a Perkin-Elmer Lambda 750 S (UV/VIS/NIR) spectrometer (both instruments from Perkin Elmer LAS, Rodgau, Germany). The solvents were dried according to usual procedures. The purity of the compounds was determined by HPLC and found to be $>96 \%$.

\subsection{Cytotoxicity}

\subsubsection{Cell Lines and Culture Conditions}

The cell lines used are human cancer cell lines: A2780 (ovarian carcinoma), HT29 (colon adenocarcinoma), MCF-7 (breast adenocarcinoma), A375 (melanoma), FaDu (pharynx squamous cell carcinoma) and non-malignant mouse fibroblasts NIH 3T3; all cell lines were obtained from the Department of Oncology (Martin-Luther-University Halle-Wittenberg). Cultures were maintained as monolayers in RPMI 1640 medium with L-glutamine (Capricorn Scientific GmbH, Ebsdorfergrund, Germany) supplemented with 10\% heat inactivated fetal bovine serum (Sigma-Aldrich Chemie GmbH, Steinheim, Germany) and penicillin/streptomycin (Capricorn Scientific GmbH, Ebsdorfergrund, Germany) at $37^{\circ} \mathrm{C}$ in a humidified atmosphere with $5 \% \mathrm{CO}_{2}$.

\subsubsection{Cytotoxic Assay (SRB)}

The cytotoxicity of the compounds was evaluated using the sulforhodamine-B (Kiton-Red S, $\mathrm{ABCR}$ ) micro culture colorimetric assay. Cells were seeded into 96-well plates on day 0 at appropriate cell densities to prevent confluence of the cells during the period of experiment. After $24 \mathrm{~h}$, the cells were treated with six different concentrations $(1,3,7,12,20$, and $30 \mu \mathrm{M})$ minimum. The final concentration of DMSO/DMF never exceeded $0.5 \%$, which was non-toxic to the cells. After a $72-\mathrm{h}$ treatment, the supernatant medium from the 96-well plates was discarded, the cells were fixed with $10 \%$ trichloroacetic acid (TCA) and allowed to rest at $4{ }^{\circ} \mathrm{C}$. After $24 \mathrm{~h}$ fixation, the cells were washed in a strip washer and dyed with SRB solution $(100 \mu \mathrm{L}, 0.4 \%$, in $1 \%$ acetic acid) for about $20 \mathrm{~min}$. After dying, the plates were washed four times with $1 \%$ acetic acid to remove the excess of the dye and allowed to air-dry overnight. Tris base solution $(200 \mu \mathrm{L}, 10 \mathrm{mM})$ was added to each well and absorbance was measured at $\lambda=570 \mathrm{~nm}$ using a 96 well plate reader (Tecan Spectra, Crailsheim, Germany). The $\mathrm{EC}_{50}$ values were averaged from three independent experiments performed each in triplicate calculated from semi logarithmic dose response curves applying a non-linear 4P Hills-slope equation (GraphPad Prism5; variables top and bottom were set to 100 and 0, respectively).

\subsubsection{AO/PI Dye Exclusion Test}

Morphological characteristics of cell death were analyzed employing an AO/PI assay using human cancer cell line A375. Approx. $2 \times 10^{5}$ cells were seeded in cell culture flasks $\left(25 \mathrm{~cm}^{2}\right)$, and the cells were allowed to grow up for $24 \mathrm{~h}$. After removing of the used medium, the substance loaded fresh medium was reloaded (or a blank new medium as a control). After $24 \mathrm{~h}$ and $48 \mathrm{~h}$, the content of the flask was collected and centrifuged $\left(1200 \mathrm{rpm}, 4^{\circ} \mathrm{C}\right)$, the pellet was gently suspended in phosphate-buffered saline (PBS (w/Ca ${ }^{2+}$ and $\left.\mathrm{Mg}^{2+}\right), 1 \mathrm{~mL}$ ) and centrifuged again. The PBS was removed, and the pellet 
gently suspended in PBS $(150 \mu \mathrm{L})$ again. The analysis of the cells was performed using a fluorescence microscope after having mixed the cell suspension $(10 \mu \mathrm{L})$ with a solution of $\mathrm{AO} / \mathrm{PI}(5 \mu \mathrm{g} / \mathrm{mL}, 10 \mu \mathrm{L})$.

\subsubsection{Annexin V-FITC/PI Assay}

Approximately $2 \times 10^{5}$ cells (A375) were seeded in cell culture flasks $\left(25 \mathrm{~cm}^{2}\right)$, and the cells were allowed to grow up for $24 \mathrm{~h}$. After removing of the used medium, the substance loaded fresh medium was reloaded (or a blank fresh medium as a control). After $24 \mathrm{~h}$ and $48 \mathrm{~h}$, the cells were harvested, centrifuged $\left(1200 \mathrm{rpm}, 4{ }^{\circ} \mathrm{C}\right)$, and washed twice with PBS (w/ $\mathrm{Ca}^{2+}$ and $\left.\mathrm{Mg}^{2+}, 1 \mathrm{~mL}\right)$. The cells were counted and approximately $1 \cdot 10^{6}$ cells were washed with Annexin V binding buffer (BioLegend ${ }^{\circledR}$, San Diego, USA) and treated with propidium iodide solution $(3 \mu \mathrm{L}, 1 \mathrm{mg} / \mathrm{mL})$ and Annexin V-FITC $\left(5 \mu \mathrm{L}\right.$, BioLegend ${ }^{\circledR}$, San Diego, CA, USA) for $15 \mathrm{~min}$ in the dark at room temperature. After adding Annexin V binding buffer $(400 \mu \mathrm{L})$ the suspension was analyzed using Attune ${ }^{\circledR}$ FACS machine. After gating for living cells, the data from detectors BL-1A and BL-3A were collected (20,000 events) in technical triplicates. The assay was performed in duplicates; cell distribution was calculated using Attune ${ }^{\circledR}$ Software (ThermoFisher Scientific, Braunschweig, Germany).

\subsubsection{Cell Cycle Investigations}

Approximately $2 \times 10^{5}$ cells (A375) were seeded in cell culture flasks $\left(25 \mathrm{~cm}^{2}\right)$, and the cells were allowed to grow up for $24 \mathrm{~h}$. After removing of the used medium, the substance loaded fresh medium was reloaded (or a blank fresh medium as a control). After $24 \mathrm{~h}$ or $48 \mathrm{~h}$, respectively, only the adherent cells were harvested, centrifuged $\left(1200 \mathrm{rpm}, 4{ }^{\circ} \mathrm{C}\right)$, and washed twice with PBS $((w / w)$, $1 \mathrm{~mL})$. The cells were counted and approximately $1 \times 10^{6}$ cells were fixed with ethanol $\left(70 \%, 4{ }^{\circ} \mathrm{C}, 24 \mathrm{~h}\right)$. After centrifugation $\left(4500 \mathrm{rpm}, 4^{\circ} \mathrm{C}\right)$ the cells were washed with PBS $((w / w), 1 \mathrm{~mL})$ and centrifuged. The pellet was resuspended in $1 \mathrm{~mL}$ RNAse A containing PI buffer $(100 \mu \mathrm{L}$ RNAse $(100 \mathrm{mg} / \mathrm{mL}), 15 \mu \mathrm{L}$ PI solution $(1 \mathrm{mg} / \mathrm{mL}))$ and after incubating for $30 \mathrm{~min}$ at room temperature in the dark, cells were analyzed using the Attune ${ }^{\circledR}$ FACS machine; collecting data from the BL-2A channel. Doublet cells were excluded from the measurements by plotting BL-2A against BL-2H. For each cell cycle distribution 20,000 events were collected in technical triplicates, each sample was measured in duplicates. Cell cycle distribution was calculated using ModFitLT ${ }^{\mathrm{TM}}$ (Verity Software House, Topsham, ME, USA).

\subsection{Syntheses}

\subsubsection{General}

Ursolic acid (1) was obtained from betulinines (Stříbrná Skalice, Czech Republic). 1,4,7,10-Tetraazacyclododecane (cyclen, 2) was bought from abcr GmbH (Karlsruhe, Germany) in $95 \%$ purity. Benzyl bromoacetate (96\%) and tert-Butyl bromoacetate $(98 \%)$ were both purchased from Sigma-Aldrich Chemie GmbH (Steinheim, Germany). DOTA-tris(tert-butyl ester) was obtained from TCI Deutschland GmbH (Eschborn, Germany) in 97\% purity. Ursolic acid derivatives 10, 16-18 and 28 have been synthesized as previously reported [20,21]. Experimental procedures and full analytical data of these compounds can be found in the supplementary material $[23,24]$.

\subsubsection{General Procedure A for the Synthesis of DOTA Precursors (6-8)}

To a suspension of cyclen $(5.81 \mathrm{mmol})$ and sodium bicarbonate $(17.43 \mathrm{mmol})$ in dry acetonitrile $(100 \mathrm{~mL})$, a solution of the respective bromoacetate $(3-5,17.43 \mathrm{mmol})$ in dry acetonitrile $(10 \mathrm{~mL})$ was added dropwise under argon atmosphere. The mixture was stirred for $48 \mathrm{~h}$ at $25^{\circ} \mathrm{C}$. After usual aqueous work-up, the solvent was removed under reduced pressure, and the crude products were subjected to column chromatography (silica gel, chloroform/methanol mixtures) affording DOTA precursors 6-8 (50-68\%). 


\subsubsection{General Procedure B for the Synthesis of Carboxamides (10, 16-18)}

Compound $9(0.5 \mathrm{mmol})$ was dissolved in dry DCM $(10 \mathrm{~mL})$, cooled to $0{ }^{\circ} \mathrm{C}$ and oxalyl chloride (3.2 mmol) and dry DMF (2 drops) were added. After warming to $25^{\circ} \mathrm{C}$, the mixture was stirred for $1 \mathrm{~h}$. The solvent was removed under reduced pressure, re-evaporated with dry THF $(4 \times 15 \mathrm{~mL})$, and the residue was immediately resolved in dry DCM $(10 \mathrm{~mL})$. This mixture was then added dropwise to a solution of the amine $(3.0 \mathrm{mmol})$ in dry DCM $(2 \mathrm{~mL})$ and stirred at $25^{\circ} \mathrm{C}$ for $2 \mathrm{~h}$. After usual aqueous work-up, the solvent was removed under reduced pressure, and the crude products were subjected to column chromatography (silica gel, chloroform/methanol mixtures). Compounds $\mathbf{1 0}$ and 16-18 were each obtained as colorless solids (78-82\%).

\subsubsection{General Procedure C for the Alkylation with Chloroacetyl Chloride (11, 19-21)}

Chloroacetyl chloride $(2.20 \mathrm{mmol})$ was added dropwise to a solution of the respective carboxamide $(\mathbf{1 0}, \mathbf{1 6}-\mathbf{1 8} ; 1.43 \mathrm{mmol})$ and triethylamine $(0.71 \mathrm{mmol})$ in dry dichloromethane $(75 \mathrm{~mL})$. The mixture was stirred at $25{ }^{\circ} \mathrm{C}$ for $0.5-4 \mathrm{~h}$. After usual aqueous work-up, the solvent was removed under reduced pressure, and the crude products were subjected to column chromatography (silica gel, chloroform/acetone mixtures). Compounds $\mathbf{1 1}$ and 19-21 were each obtained as colorless solids $(91 \%-94 \%)$.

\subsubsection{General Procedure D for the Synthesis of Ursolic Acid Chelator Conjugates (12-14, 22-27)}

To a solution of the respective chloroacetyl derivative $(\mathbf{1 1}, \mathbf{1 9 - 2 1} ; 0.44 \mathrm{mmol})$ and freshly grounded potassium carbonate $(0.83 \mathrm{mmol})$ in dry acetonitrile $(15 \mathrm{~mL})$ was added potassium iodide $(0.35 \mathrm{mmol})$ and the respective DOTA precursor $(6-8,0.41 \mathrm{mmol}$ in $5 \mathrm{~mL}$ dry acetonitrile). The mixture was stirred for 2-5 days at $25^{\circ} \mathrm{C}$. After completion of the reaction (as indicated by TLC) the mixture was filtered, and the solvent was removed under reduced pressure. The crude products were subjected to column chromatography (silica gel, chloroform/methanol mixtures) to afford compounds 12-14 and 22-27 (yield: 54-88\%), respectively.

Allyl bromoacetate (5), To a solution of allyl alcohol (0.62 mol), bromo acetylbromide (0.1 mol) was added dropwise over a period of $30 \mathrm{~min}$ at $0{ }^{\circ} \mathrm{C}$ under argon atmosphere. The mixture was stirred for $1 \mathrm{~h}$ at $0{ }^{\circ} \mathrm{C}$, warmed to $25^{\circ} \mathrm{C}$ and stirred for another $3 \mathrm{~h}$. The solvent was removed under reduced pressure and the residue was dissolved in dichloromethane. After usual aqueous work-up, the solvent was removed under reduced pressure, and the crude product was purified by vacuum distillation affording allyl bromoacetate as colorless oil (68\%). ${ }^{1} \mathrm{H}$ NMR $\left(400 \mathrm{MHz}, \mathrm{CDCl}_{3}\right): \delta=5.88(d d t, J=16.5,11.0$, $\left.5.8 \mathrm{~Hz}, 1 \mathrm{H}, \mathrm{CH}=\mathrm{CH}_{2}\right), 5.38-5.17\left(m, 2 \mathrm{H}, \mathrm{CH}=\mathrm{CH}_{2}\right), 4.61\left(d t, J=5.8,1.4 \mathrm{~Hz}, 2 \mathrm{H}, \mathrm{CH}_{2} \mathrm{CH}^{2} \mathrm{CH}_{2}\right), 3.82$ $\left(\mathrm{s}, 2 \mathrm{H}, \mathrm{BrCH}_{2}\right) \mathrm{ppm} ;{ }^{13} \mathrm{C} \mathrm{NMR}\left(101 \mathrm{MHz}, \mathrm{CDCl}_{3}\right): \delta=166.8(\mathrm{C}=\mathrm{O}), 131.2\left(\mathrm{CH}=\mathrm{CH}_{2}\right), 119.0\left(\mathrm{CH}^{2} \mathrm{CH}_{2}\right)$, $66.6\left(\mathrm{CH}_{2} \mathrm{CH}=\mathrm{CH}_{2}\right), 25.8\left(\mathrm{BrCH}_{2}\right)$ ppm.

Tri-tert-butyl 2,2' ,2"-(1,4,7,10-tetraazacyclododecane-1,4,7-triyl)triacetate (6), Compound 6 was prepared from 2 according to general procedure A using tert-butyl bromoacetate (3). Column chromatography $\left(\mathrm{SiO}_{2}, \mathrm{CHCl}_{3} / \mathrm{MeOH} 9: 1\right.$ ) gave 6 (yield: 50\%); m.p. $180-182{ }^{\circ} \mathrm{C}$ (lit.: 181-183 ${ }^{\circ} \mathrm{C}$ [25]); $\mathrm{R}_{\mathrm{f}}=0.27$ $\left(\mathrm{CHCl}_{3} / \mathrm{MeOH} 95: 5\right) ;$ IR (ATR): $v=2974 w, 2943 w, 2912 w, 2853 w, 2736 w, 1718 s, 1576 w, 1466 w, 1453 w$, $1412 w, 1392 w, 1368 m, 1330 w, 1255 m, 1218 w, 1147 s, 1117 m, 1099 m, 1050 w, 935 m, 873 m, 848 m \mathrm{~cm}^{-1}$; ${ }^{1} \mathrm{H}$ NMR $\left(400 \mathrm{MHz}_{2} \mathrm{CDCl}_{3}\right): \delta=3.36\left(s, 4 \mathrm{H}, 2 \times \mathrm{CH}_{2}\right.$ (acetate)), $3.28\left(s, 2 \mathrm{H}, \mathrm{CH}_{2}\right.$ (acetate)), $3.12-3.06$ $\left(m, 4 \mathrm{H}, 2 \times \mathrm{CH}_{2}\right.$ (cyclen)), 2.95-2.84 ( $m, 12 \mathrm{H}, 6 \times \mathrm{CH}_{2}$ (cyclen)), $1.45\left(s, 18 \mathrm{H}, 6 \times \mathrm{CH}_{3}\right.$ (t-butyl)), $1.45(s, 9 \mathrm{H}$, $3 \times \mathrm{CH}_{3}(t$-butyl) $) \mathrm{ppm} ;{ }^{13} \mathrm{C} \mathrm{NMR}\left(101 \mathrm{MHz} \mathrm{CDCl}_{3}\right): \delta=170.6(2 \times \mathrm{CO}$, acetate), $169.8(\mathrm{CO}$, acetate), $81.9\left(\mathrm{C}_{\mathrm{q}}, t\right.$-butyl $), 81.8\left(2 \times \mathrm{C}_{\mathrm{q}}, t\right.$-butyl $), 58.4\left(2 \times \mathrm{CH}_{2}\right.$, acetate $), 51.5\left(2 \times \mathrm{CH}_{2}\right.$, cyclen $), 51.4\left(2 \times \mathrm{CH}_{2}\right.$, cyclen), $49.4\left(2 \times \mathrm{CH}_{2}\right.$, cyclen), $49.0\left(\mathrm{CH}_{2}\right.$, acetate $), 47.7\left(2 \times \mathrm{CH}_{2}\right.$, cyclen $), 28.4\left(3 \times \mathrm{CH}_{3}, t\right.$-butyl), $28.3\left(6 \times \mathrm{CH}_{3}, t\right.$-butyl) ppm; MS (ESI, MeOH): $m / z=515.3\left(100 \%,[\mathrm{M}+\mathrm{H}]^{+}\right), 537.3\left(10 \%,[\mathrm{M}+\mathrm{Na}]^{+}\right)$; analysis calcd for $\mathrm{C}_{26} \mathrm{H}_{50} \mathrm{~N}_{4} \mathrm{O}_{6}$ (514.71): C 60.67, H 9.79, N 10.89; found: C 60.51, H 9.98, N 10.67. 
Tribenzyl 2,2',2"-(1,4,7,10-tetraazacyclododecane-1,4,7-triyl)triacetate (7). Compound 7 was prepared from 2 according to general procedure A using benzyl bromoacetate (4). Column chromatography $\left(\mathrm{SiO}_{2}, \mathrm{CHCl}_{3} / \mathrm{MeOH} 9: 1\right)$ gave 7 (yield: 68\%); $\mathrm{R}_{\mathrm{f}}=0.32\left(\mathrm{CHCl}_{3} / \mathrm{MeOH} 95: 5\right) ; \mathrm{IR}(\mathrm{KBr}): v=2948 w, 2857 w$, 2738w, 1732s, 1586w, 1498w, 1455m, 1418w, 1381w, 1314w, 1169s, 1096m, 1049m, 994m, 739s, 697s cm ${ }^{-1}$; UV-Vis $\left(\mathrm{CHCl}_{3}\right): \lambda_{\max }(\log \varepsilon)=251 \mathrm{~nm}(2.87), 258 \mathrm{~nm}(2.86), 263 \mathrm{~nm}(2.76) ;{ }^{1} \mathrm{H} \mathrm{NMR}\left(400 \mathrm{MHz}, \mathrm{CDCl}_{3}\right)$ : $\delta=7.40-7.29(m, 15 \mathrm{H}, 15 \times \mathrm{CH}(\mathrm{Bn})), 5.13\left(\mathrm{~s}, 4 \mathrm{H}, 2 \times \mathrm{CH}_{2}(\mathrm{Bn})\right), 5.13\left(\mathrm{~s}, 2 \mathrm{H}, \mathrm{CH}_{2}(\mathrm{Bn})\right), 3.48(\mathrm{~s}, 4 \mathrm{H}$, $2 \times \mathrm{CH}_{2}$ (acetate)), 3.41 (s, 2H, $\mathrm{CH}_{2}$ (acetate)), 3.12-3.05 ( $m, 4 \mathrm{H}, 2 \times \mathrm{CH}_{2}$ (cyclen)), 2.93-2.79 $(\mathrm{m}, 12 \mathrm{H}$, $6 \times \mathrm{CH}_{2}$ (cyclen)) ppm; ${ }^{13} \mathrm{C}$ NMR $\left(101 \mathrm{MHz}, \mathrm{CDCl}_{3}\right): \delta=171.1(2 \times \mathrm{CO}$, acetate), 170.3 (CO, acetate), $135.5\left(\mathrm{C}_{\mathrm{i}}, \mathrm{Bn}\right), 128.8(\mathrm{CH}, \mathrm{Bn}), 128.8(\mathrm{CH}, \mathrm{Bn}), 128.7(\mathrm{CH}, \mathrm{Bn}), 128.7(\mathrm{CH}, \mathrm{Bn}), 128.6(\mathrm{CH}, \mathrm{Bn}), 66.8$ $\left(\mathrm{CH}_{2}, \mathrm{Bn}\right), 57.4\left(2 \times \mathrm{CH}_{2}\right.$, acetate $), 51.9\left(2 \times \mathrm{CH}_{2}\right.$, cyclen $), 51.7\left(2 \times \mathrm{CH}_{2}\right.$, cyclen $), 49.6\left(2 \times \mathrm{CH}_{2}\right.$, cyclen $)$, $48.8\left(\mathrm{CH}_{2}\right.$, acetate $), 47.5\left(2 \times \mathrm{CH}_{2}\right.$, cyclen) ppm; MS (ESI, MeOH): $\mathrm{m} / \mathrm{z}=309.0\left(10 \%,[\mathrm{M}+2 \mathrm{H}]^{2+}\right), 617.4$ $\left(100 \%,[\mathrm{M}+\mathrm{H}]^{+}\right), 639.3\left(10 \%,[\mathrm{M}+\mathrm{Na}]^{+}\right)$; analysis calcd for $\mathrm{C}_{35} \mathrm{H}_{44} \mathrm{~N}_{4} \mathrm{O}_{6}(616.76): \mathrm{C} 68.16, \mathrm{H}$ 7.19, N 9.08; found: C 67.84, H 7.39, N 8.81.

Triallyl 2,2',2"-(1,4,7,10-tetraazacyclododecane-1,4,7-triyl)triacetate (8), Compound 8 was prepared from 2 according to general procedure A using allyl bromoacetate (5). Column chromatography $\left(\mathrm{SiO}_{2}, \mathrm{CHCl}_{3} / \mathrm{MeOH} 95: 5\right)$ gave 8 (yield: 63\%); $\mathrm{R}_{\mathrm{f}}=0.27\left(\mathrm{CHCl}_{3} / \mathrm{MeOH} 95: 5\right) ; \mathrm{IR}(\mathrm{KBr}): v=2945 w$, $2858 w, 2743 w, 1731 s, 1673 w, 1648 w, 1455 w, 1420 w, 1364 w, 1314 w, 1179 s, 1095 \mathrm{~m}, 985 \mathrm{~s}, 928 \mathrm{~cm}^{-1}$; ${ }^{1} \mathrm{H}$ NMR $\left(400 \mathrm{MHz}, \mathrm{CDCl}_{3}\right): \delta=5.93-5.81\left(\mathrm{~m}, 3 \mathrm{H}, 3 \times \mathrm{CH}\right.$ (allyl)), 5.32-5.20 $\left(\mathrm{m}, 6 \mathrm{H}, 3 \times \mathrm{CH}_{2}\right.$ (allyl)), 4.60-4.53 (m, 6H, $3 \times \mathrm{CH}_{2}$ (allyl)), $3.49\left(\mathrm{~s}, 4 \mathrm{H}, 2 \times \mathrm{CH}_{2}\right.$ (acetate)), $3.41\left(\mathrm{~s}, 2 \mathrm{H}, \mathrm{CH}_{2}\right.$ (acetate)), 3.12-3.06 ( $m, 4 \mathrm{H}, 2 \times \mathrm{CH}_{2}$ (cyclen)), 2.96-2.81 ( $m, 12 \mathrm{H}, 6 \times \mathrm{CH}_{2}$ (cyclen)) ppm; ${ }^{13} \mathrm{C} \mathrm{NMR}\left(101 \mathrm{MHz}, \mathrm{CDCl}_{3}\right)$ : $\delta=170.8(2 \times \mathrm{CO}$, acetate $), 170.0(\mathrm{CO}$, acetate $), 131.7(2 \times \mathrm{CH}$, allyl $), 131.7(\mathrm{CH}$, allyl $), 119.2\left(\mathrm{CH}_{2}\right.$, allyl $)$, $119.0\left(2 \times \mathrm{CH}_{2}\right.$, allyl), $65.5\left(2 \times \mathrm{CH}_{2}\right.$, allyl $), 65.4\left(\mathrm{CH}_{2}\right.$, allyl $), 57.3\left(2 \times \mathrm{CH}_{2}\right.$, acetate $), 51.7\left(2 \times \mathrm{CH}_{2}\right.$, cyclen), $51.6\left(2 \times \mathrm{CH}_{2}\right.$, cyclen $), 49.4\left(2 \times \mathrm{CH}_{2}\right.$, cyclen $), 48.5\left(\mathrm{CH}_{2}\right.$, acetate $), 47.4\left(\mathrm{CH}_{2}\right.$, cyclen $) \mathrm{ppm}$; MS (ESI, MeOH): $m / z=234.1\left(18 \%,[\mathrm{M}+2 \mathrm{H}]^{2+}\right), 467.3\left(100 \%,[\mathrm{M}+\mathrm{H}]^{+}\right), 489.3\left(10 \%,[\mathrm{M}+\mathrm{Na}]^{+}\right)$; analysis calcd for $\mathrm{C}_{23} \mathrm{H}_{38} \mathrm{~N}_{4} \mathrm{O}_{6}$ (466.6): C 59.21, $\mathrm{H}$ 8.21, N 12.01; found: C 59.03, H 8.44, N 11.78.

(3ß) 3-Acetyloxy-urs-12-en-28-oic acid (9), Compound 1 was prepared from ursolic acid according to the procedure given in the literature [26]. Yield: $96 \%$; m.p. $287-290{ }^{\circ} \mathrm{C}$ (lit.: $289-290{ }^{\circ} \mathrm{C}$ [27]).

(3ß) N-(2-(4-(2-Chloroacetyl)piperazin-1-yl)ethyl)-3-acetyloxy-urs-12-en-28-amide (11). Compound 11 was synthesized from 10 according to general procedure $\mathrm{C}$. Column chromatography $\left(\mathrm{SiO}_{2}, \mathrm{CHCl}_{3} /\right.$ acetone 4:1) furnished compound 11 (91\%); m.p. $124-129^{\circ} \mathrm{C} ;[\alpha]_{\mathrm{D}}=+32.3^{\circ}$ (c $\left.0.320, \mathrm{CHCl}_{3}\right) ; \mathrm{R}_{\mathrm{f}}=0.38$ $\left(\mathrm{CHCl}_{3}\right.$ /acetone 4:1); IR (KBr): $v=3423 \mathrm{~s}, 2947 \mathrm{~s}, 1734 m, 1654 s, 1522 m, 1458 m, 1370 m, 1247 \mathrm{~s}, 1150 w$, $1027 \mathrm{~m} \mathrm{~cm}^{-1} ;{ }^{1} \mathrm{H}$ NMR $\left(400 \mathrm{MHz}, \mathrm{CDCl}_{3}\right): \delta=6.32(t, J=5.0 \mathrm{~Hz}, 1 \mathrm{H}, \mathrm{NH}), 5.28(t, J=3.6 \mathrm{~Hz}, 1 \mathrm{H}, 12-\mathrm{H})$, $4.49(d d, J=10.4,5.4 \mathrm{~Hz}, 1 \mathrm{H}, 3-\mathrm{H}), 4.06(s, 2 \mathrm{H}, 36-\mathrm{H}), 3.72-3.47\left(m, 4 \mathrm{H}, 34-\mathrm{H}, 34^{\prime}-\mathrm{H}\right), 3.47-3.36(m, 1 \mathrm{H}$, 31- $\left.\mathrm{H}_{\mathrm{a}}\right), 3.25-3.15\left(m, 1 \mathrm{H}, 31-\mathrm{H}_{\mathrm{b}}\right), 2.58-2.39\left(m, 6 \mathrm{H}, 33-\mathrm{H}, 32-\mathrm{H}, 33^{\prime}-\mathrm{H}\right), 2.04(\mathrm{~s}, 3 \mathrm{H}, \mathrm{Ac}), 2.02-1.80(m, 5 \mathrm{H}$, $\left.11-\mathrm{H}_{\mathrm{a}}, 11-\mathrm{H}_{\mathrm{b}}, 16-\mathrm{H}_{\mathrm{a}}, 22-\mathrm{H}_{\mathrm{a}}, 18-\mathrm{H}\right), 1.79-1.70\left(m, 1 \mathrm{H}, 16-\mathrm{H}_{\mathrm{b}}\right), 1.69-1.21\left(m, 13 \mathrm{H}, 15-\mathrm{H}_{\mathrm{a}}, 1-\mathrm{H}_{\mathrm{a}}, 2-\mathrm{H}_{\mathrm{a}}, 2-\mathrm{H}_{\mathrm{b}}\right.$, 9- $\left.\mathrm{H}, 6-\mathrm{H}_{\mathrm{a}}, 21-\mathrm{H}_{\mathrm{a}}, 7-\mathrm{H}_{\mathrm{a}}, 22-\mathrm{H}_{\mathrm{b}}, 19-\mathrm{H}, 6-\mathrm{H}_{\mathrm{b}}, 21-\mathrm{H}_{\mathrm{b}}, 7-\mathrm{H}_{\mathrm{b}}\right), 1.09(\mathrm{~s}, 3 \mathrm{H}, 27-\mathrm{H}), 1.08-1.01\left(m, 2 \mathrm{H}, 1-\mathrm{H}_{\mathrm{b}}\right.$, $\left.15-\mathrm{H}_{\mathrm{b}}\right), 0.96-0.94(m, 4 \mathrm{H}, 20-\mathrm{H}, 30-\mathrm{H}), 0.93(\mathrm{~s}, 3 \mathrm{H}, 25-\mathrm{H}), 0.89-0.86(m, 3 \mathrm{H}, 29-\mathrm{H}), 0.86(\mathrm{~s}, 3 \mathrm{H}, 23-\mathrm{H}), 0.85$ $(\mathrm{s}, 3 \mathrm{H}, 24-\mathrm{H}), 0.84-0.79(\mathrm{~m}, 1 \mathrm{H}, 5-\mathrm{H}), 0.78(\mathrm{~s}, 3 \mathrm{H}, 26-\mathrm{H}) \mathrm{ppm} ;{ }^{13} \mathrm{C} \mathrm{NMR}\left(101 \mathrm{MHz}, \mathrm{CDCl}_{3}\right): \delta=178.1$ (C-28), 171.1 (Ac), 165.2 (C-35), 140.0 (C-13), 125.3 (C-12), 80.9 (C-3), 56.7 (C-32), 55.4 (C-5), 54.2 (C-18), 53.0 (C-33), 52.5 (C-33'), 48.0 (C-17), 47.6 (C-9), 46.5 (C-34), 42.6 (C-14), 42.4 (C-34'), 40.9 (C-36), 39.9 (C-19), 39.7 (C-8), 39.3 (C-20) 38.4 (C-1), 37.8 (C-4), 37.5 (C-22), 37.0 (C-10), 35.9 (C-31), 32.8 (C-7), 31.0 (C-21), 28.2 (C-23), 28.0 (C-15), 25.0 (C-16), 23.6 (C-2), 23.6 (C-11), 23.4 (C-27), 21.4 (Ac), 21.3 (C-30), 18.3 (C-6), 17.5 (C-29), 17.1 (C-26), 16.9 (C-24), 15.8 (C-25) ppm; MS (ESI, MeOH): m/z = $686.5(100 \%$, $\left.[\mathrm{M}+\mathrm{H}]^{+}\right)$; analysis calcd for $\mathrm{C}_{40} \mathrm{H}_{64} \mathrm{ClN}_{3} \mathrm{O}_{4}$ (686.42): $\mathrm{C}$ 69.99, $\mathrm{H}$ 9.40, $\mathrm{N}$ 6.12; found: $\mathrm{C} 69.70, \mathrm{H} 9.63$, $\mathrm{N} 6.02$.

Tris-t-butyl 2',2"-[10-[2-[4-[2-(3ß-acetyloxy-urs-12-en-28-oylamino)ethyl]piperazin-1-yl]-2-oxoethyl]-1,4,7,10tetraazacyclododecane-1,4,7-triyl]triacetate (12), Compound $\mathbf{1 2}$ was synthesized from $\mathbf{6}$ and $\mathbf{1 1}$ according to general procedure D. Column chromatography $\left(\mathrm{SiO}_{2}, \mathrm{CHCl}_{3} / \mathrm{MeOH}\right.$ 9:1) furnished compound 
12 (54\%). m.p. $247-250{ }^{\circ} \mathrm{C}$ (decomp.); $[\alpha]_{\mathrm{D}}=+18.9^{\circ}\left(\mathrm{c} 0.345, \mathrm{CHCl}_{3}\right) ; \mathrm{R}_{\mathrm{f}}=0.30\left(\mathrm{CHCl}_{3} / \mathrm{MeOH} 9: 1\right)$; IR (KBr): $v=2931 m, 1727 s, 1644 s, 1529 w, 1455 m, 1425 w, 1368 s, 1306 m, 1228 s, 1159 s, 1105 s, 1005 m$, $755 \mathrm{~m} \mathrm{~cm}^{-1} ;{ }^{1} \mathrm{H}$ NMR $\left(400 \mathrm{MHz}, \mathrm{CDCl}_{3}\right): \delta=6.38(s, 1 \mathrm{H}, \mathrm{NH}), 5.26(t, J=3.4 \mathrm{~Hz}, 1 \mathrm{H}, 12-\mathrm{H}), 4.46$ $(d d, J=10.5,5.2 \mathrm{~Hz}, 1 \mathrm{H}, 3-\mathrm{H}), 3.92-2.04\left(m, 36 \mathrm{H}, 34-\mathrm{H}, 34^{\prime}-\mathrm{H}, 36-\mathrm{H}, 3 \times \mathrm{CH}_{2}\right.$ (acetate), 31- $\mathrm{H}_{\mathrm{a}}, 31-\mathrm{H}_{\mathrm{b}}$, $8 \times \mathrm{CH}_{2}$ (cyclen), 32-H, 33-H, 33'-H), 2.01 (s, 3H, Ac), 2.00-1.68 (m, 4H, 16- $\left.\mathrm{H}_{\mathrm{a}}, 11-\mathrm{H}_{\mathrm{a}}, 11-\mathrm{H}_{\mathrm{b}}, 18-\mathrm{H}\right)$, 1.69-1.14 (m, 14H, 16- $\mathrm{H}_{\mathrm{b}}, 22-\mathrm{H}_{\mathrm{b}}, 15-\mathrm{H}_{\mathrm{a}}, 1-\mathrm{H}_{\mathrm{a}}, 2-\mathrm{H}_{\mathrm{a}}, 2-\mathrm{H}_{\mathrm{b}}, 9-\mathrm{H}, 6-\mathrm{H}_{\mathrm{a}}, 21-\mathrm{H}_{\mathrm{a}}, 7-\mathrm{H}_{\mathrm{a}}, 19-\mathrm{H}, 6-\mathrm{H}_{\mathrm{b}}, 21-\mathrm{H}_{\mathrm{b}}$, 7- $\left.\mathrm{H}_{\mathrm{b}}\right), 1.42\left(\mathrm{~s}, 27 \mathrm{H}, 9 \times \mathrm{CH}_{3}\right.$ (t-Butyl)), $1.05(\mathrm{~s}, 3 \mathrm{H}, 27-\mathrm{H}), 1.11-0.95\left(m, 3 \mathrm{H}, 1-\mathrm{H}_{\mathrm{b}}, 15-\mathrm{H}_{\mathrm{b}}, 20-\mathrm{H}\right), 0.91$ $(d, J=6.1 \mathrm{~Hz}, 3 \mathrm{H}, 30-\mathrm{H}), 0.90(s, 3 \mathrm{H}, 25-\mathrm{H}), 0.85(d, J=6.5 \mathrm{~Hz}, 3 \mathrm{H}, 29-\mathrm{H}), 0.83(s, 3 \mathrm{H}, 23-\mathrm{H}), 0.82(s, 3 \mathrm{H}$, 24-H), 0.80-0.75 (m, 1H, 5-H), $0.74(\mathrm{~s}, 3 \mathrm{H}, 26-\mathrm{H}) \mathrm{ppm} ;{ }^{13} \mathrm{C} \mathrm{NMR}\left(100 \mathrm{MHz}, \mathrm{CDCl}_{3}\right): \delta=178.0(\mathrm{C}-28)$, 172.8 (CO, acetate), 171.0 (Ac), 169.8 (C-35), 139.8 (C-13), 125.3 (C-12), $81.9\left(\mathrm{C}_{\mathrm{q}}, t\right.$-Butyl), $81.7\left(2 \times \mathrm{C}_{\mathrm{q}}\right.$, t-Butyl), 80.9 (C-3), 56.8 (C-32), $55.8\left(3 \times \mathrm{CH}_{2}\right.$, acetate), $55.3(\mathrm{C}-5), 55.2(\mathrm{C}-36), 53.9(\mathrm{C}-18), 53.4\left(8 \times \mathrm{CH}_{2}\right.$, cyclen), 52.2 (C-33, C-33'), 47.8 (C-17), 47.5 (C-9), 44.3 (C-34, C-34'), 42.5 (C-14), 39.8 (C-19), 39.7 (C-8), 39.1 (C-20), 38.4 (C-1), 37.8 (C-4), 37.4 (C-22), 36.9 (C-10), 35.7 (C-31), 32.8 (C-7), 31.0 (C-21), 28.2 (C-23), $28.0\left(9 \times \mathrm{CH}_{3}, \mathrm{t}-\mathrm{Butyl}\right), 27.9$ (C-15), 24.8 (C-16), 23.6 (C-2), 23.5 (C-11), 23.4 (C-27), 21.4 (Ac), 21.3 (C-30), 18.3 (C-6), 17.4 (C-29), 17.1 (C-26), 16.8 (C-24), 15.7 (C-25) ppm; MS (ESI, MeOH): $\mathrm{m} / z=593.9$ (100\%, $\left.[\mathrm{M}+\mathrm{Na}+\mathrm{H}]^{+}\right), 1186.7\left(95 \%,[\mathrm{M}+\mathrm{Na}]^{+}\right)$; analysis calcd for $\mathrm{C}_{66} \mathrm{H}_{113} \mathrm{~N}_{7} \mathrm{O}_{10}$ (1164.67): C 68.06, H 9.78, N 8.42; found: C 67.75, H 9.97, N 8.51.

Tribenzyl 2,2',2"-[10-[2-[4-[2-(3ß-acetyloxy-urs-12-en-28-oylamino)ethyl]piperazin-1-yl]-2-oxoethyl]-1,4,7,10tetraazacyclododecane-1,4,7-triyl] triacetate (13). Compound $\mathbf{1 3}$ was synthesized from $\mathbf{7}$ and $\mathbf{1 1}$ according to general procedure D. Column chromatography $\left(\mathrm{SiO}_{2}, \mathrm{CHCl}_{3} / \mathrm{MeOH} 95: 5\right)$ furnished compound $13(82 \%)$. m.p. $142-146{ }^{\circ} \mathrm{C} ;[\alpha]_{\mathrm{D}}=+14.5^{\circ}\left(\mathrm{c} 0.300, \mathrm{CHCl}_{3}\right) ; \mathrm{R}_{\mathrm{f}}=0.50\left(\mathrm{CHCl}_{3} / \mathrm{MeOH} 9: 1\right) ; \mathrm{IR}(\mathrm{KBr})$ : $v=3440 \mathrm{~s}, 2947 \mathrm{~m}, 1734 \mathrm{~s}, 1641 \mathrm{~s}, 1456 \mathrm{~m}, 1371 \mathrm{~m}, 1310 \mathrm{w}, 1247 \mathrm{~m}, 1197 \mathrm{~s}, 1105 \mathrm{~m}, 1006 \mathrm{w}, 750 \mathrm{~m} \mathrm{~cm}^{-1}$; UV-Vis $\left(\mathrm{CHCl}_{3}\right): \lambda_{\max }(\log \varepsilon)=257 \mathrm{~nm}(3.99) ;{ }^{1} \mathrm{H} \mathrm{NMR}\left(400 \mathrm{MHz}, \mathrm{CDCl}_{3}\right): \delta=7.36-7.24\left(m, 15 \mathrm{H}, \mathrm{CH}_{\mathrm{Ar}}\right)$, 6.36-6.28 ( $m, 1 \mathrm{H}, \mathrm{NH}), 5.27(t, J=3.7 \mathrm{~Hz}, 1 \mathrm{H}, 12-\mathrm{H}), 5.21-5.13\left(m, 4 \mathrm{H}, 2 \times \mathrm{CH}_{2} \mathrm{Bn}\right), 5.12-5.05(m, 2 \mathrm{H}$, $\left.\mathrm{CH}_{2} \mathrm{Bn}\right), 4.47(d d, J=10.7,5.1 \mathrm{~Hz}, 1 \mathrm{H}, 3-\mathrm{H}), 3.72-2.81\left(m, 12 \mathrm{H}, 34-\mathrm{H}, 34^{\prime}-\mathrm{H}, 36-\mathrm{H}, 3 \times \mathrm{CH}_{2}\right.$ (acetate)), 3.40-3.30 (m, 1H, 31- $\left.\mathrm{H}_{\mathrm{a}}\right), 3.22-3.14\left(m, 1 \mathrm{H}, 31-\mathrm{H}_{\mathrm{b}}\right), 2.46-2.33\left(m, 6 \mathrm{H}, 32-\mathrm{H}, 33-\mathrm{H}, 33^{\prime}-\mathrm{H}\right), 2.81-2.06$ $\left(m, 16 \mathrm{H}, 8 \times \mathrm{CH}_{2}\right.$ (cyclen)), $2.03(\mathrm{~s}, 3 \mathrm{H}, \mathrm{Ac}), 2.00-1.68\left(m, 6 \mathrm{H}, 16-\mathrm{H}_{\mathrm{a}}, 11-\mathrm{H}_{\mathrm{a}}, 11-\mathrm{H}_{\mathrm{b}}, 18-\mathrm{H}, 22-\mathrm{H}_{\mathrm{a}}, 16-\mathrm{H}_{\mathrm{b}}\right)$, 1.68-1.20 (m, 13H, 15- $\left.\mathrm{H}_{\mathrm{a}}, 1-\mathrm{H}_{\mathrm{a}}, 2-\mathrm{H}_{\mathrm{a}}, 2-\mathrm{H}_{\mathrm{b}}, 9-\mathrm{H}, 6-\mathrm{H}_{\mathrm{a}}, 21-\mathrm{H}_{\mathrm{a}}, 7-\mathrm{H}_{\mathrm{a}}, 22-\mathrm{H}_{\mathrm{b}}, 19-\mathrm{H}, 6-\mathrm{H}_{\mathrm{b}}, 21-\mathrm{H}_{\mathrm{b}}, 7-\mathrm{H}_{\mathrm{b}}\right)$, $1.06(s, 3 \mathrm{H}, 27-\mathrm{H}), 1.05-0.94\left(m, 3 \mathrm{H}, 1-\mathrm{H}_{\mathrm{b}}, 15-\mathrm{H}_{\mathrm{b}}, 20-\mathrm{H}\right), 0.93(\mathrm{brs}, 3 \mathrm{H}, 30-\mathrm{H}), 0.91(\mathrm{~s}, 3 \mathrm{H}, 25-\mathrm{H}), 0.85$ $(d, J=5.7 \mathrm{~Hz}, 3 \mathrm{H}, 29-\mathrm{H}), 0.85(s, 3 \mathrm{H}, 23-\mathrm{H}), 0.83(s, 3 \mathrm{H}, 24-\mathrm{H}), 0.82-0.77(m, 1 \mathrm{H}, 5-\mathrm{H}), 0.76(s, 3 \mathrm{H}, 26-\mathrm{H})$ ppm; ${ }^{13} \mathrm{C} \mathrm{NMR}\left(101 \mathrm{MHz}, \mathrm{CDCl}_{3}\right): \delta=177.9$ (C-28), 173.5 (CO, acetate), 170.9 (Ac), 170.0 (C-35), 139.7 (C-13), $135.4\left(\mathrm{C}_{\mathrm{Ar}}\right), 135.3\left(\mathrm{C}_{\mathrm{Ar}}\right), 135.2\left(\mathrm{C}_{\mathrm{Ar}}\right), 128.7\left(\mathrm{CH}_{\mathrm{Ar}}\right), 128.6\left(\mathrm{CH}_{\mathrm{Ar}}\right), 128.5\left(\mathrm{CH}_{\mathrm{Ar}}\right), 128.3\left(\mathrm{CH}_{\mathrm{Ar}}\right)$, $128.3\left(\mathrm{CH}_{\mathrm{Ar}}\right), 128.2\left(\mathrm{CH}_{\mathrm{Ar}}\right), 125.3\left(\mathrm{CH}_{\mathrm{Ar}}\right), 80.8(\mathrm{C}-3), 67.0\left(\mathrm{CH}_{2}, \mathrm{Bn}\right), 66.8\left(\mathrm{CH}_{2}, \mathrm{Bn}\right), 56.7(\mathrm{C}-32), 55.4$ (C-36), $55.3\left(\mathrm{CH}_{2}\right.$, acetate), 55.2 (C-5), 53.9 (C-18), $53.4\left(\mathrm{CH}_{2}\right.$, cyclen), 52.7 (C-33, C-33'), 47.7 (C-17), 47.4 (C-9), 42.4 (C-14), 39.7 (C-19), 39.5 (C-8), 39.0 (C-20), 38.3 (C-1), 37.6 (C-4), 37.3 (C-22), 36.8 (C-10), 35.8 (C-31), 32.7 (C-7), 30.9 (C-21), 28.0 (C-23), 27.8 (C-15), 24.8 (C-16), 23.5 (C-2), 23.4 (C-11), 23.2 (C-27), 21.3 (Ac), 21.2 (C-30), 18.1 (C-6), 17.3 (C-29), 17.0 (C-26), 16.7 (C-24), 15.6 (C-25) ppm; MS (ESI, MeOH): $m / z=634\left(20 \%,[\mathrm{M}+2 \mathrm{H}]^{2+}\right), 645\left(100 \%,[\mathrm{M}+\mathrm{H}+\mathrm{Na}]^{2+}\right), 1289\left(62 \%,[\mathrm{M}+\mathrm{Na}]^{+}\right)$; analysis calcd for $\mathrm{C}_{75} \mathrm{H}_{107} \mathrm{~N}_{7} \mathrm{O}_{10}$ (1266.72): C 71.11, H 8.51, N 7.74; found: C 70.73, H 8.70, N 7.49.

Triallyl 2,2',2"-[10-[2-[4-[2-(3ß-acetyloxy-urs-12-en-28-oylamino)ethyl]piperazin-1-yl]-2-oxoethyl]-1,4,7,10tetraazacyclododecane-1,4,7-triyl]triacetate (14). Compound $\mathbf{1 4}$ was synthesized from $\mathbf{8}$ and $\mathbf{1 1}$ according to general procedure $\mathrm{D}$. Column chromatography $\left(\mathrm{SiO}_{2}, \mathrm{CHCl}_{3} / \mathrm{MeOH} 95: 5\right)$ furnished compound 14 (80\%); m.p. $159-163{ }^{\circ} \mathrm{C}$ (decomp.); $[\alpha]_{\mathrm{D}}=+14.8^{\circ}$ (c 0.310, $\left.\mathrm{CHCl}_{3}\right) ; \mathrm{R}_{\mathrm{f}}=0.35\left(\mathrm{SiO}_{2}, \mathrm{CHCl} / \mathrm{MeOH} 9: 1\right)$; IR (KBr): $v=3342 s, 2946 m, 2852 w, 1734 s, 1642 s, 1522 w, 1456 m, 1386 w, 1310 w, 1246 m, 1202 m, 1106 m$, $1026 w \mathrm{~cm}^{-1} ;{ }^{1} \mathrm{H}$ NMR $\left(400 \mathrm{MHz}, \mathrm{CDCl}_{3}\right): \delta=6.35(\mathrm{~s}, 1 \mathrm{H}, \mathrm{NH}), 5.97-5.83(\mathrm{~m}, 3 \mathrm{H}, 3 \times \mathrm{CH}$ (allyl)), 5.34-5.19 (m, 7H, 12-H, $3 \times \mathrm{CH}_{2}$ (allyl)), 4.67-4.55 (m, 6H, $3 \times \mathrm{CH}_{2}$ (allyl)), $4.47(d d, J=10.6,5.3 \mathrm{~Hz}$, $1 \mathrm{H}, 3-\mathrm{H}), 3.72-2.97\left(m, 14 \mathrm{H}, 34-\mathrm{H}, 34^{\prime}-\mathrm{H}, 36-\mathrm{H}, 3 \times \mathrm{CH}_{2}\right.$ (acetate), 31- $\left.\mathrm{H}_{\mathrm{a}}, 31-\mathrm{H}_{\mathrm{b}}\right), 2.97-2.14(m, 22 \mathrm{H}$, $8 \times \mathrm{CH}_{2}$ (cyclen), 32- $\left.\mathrm{H}, 33-\mathrm{H}, 33^{\prime}-\mathrm{H}\right), 2.03(\mathrm{~s}, 3 \mathrm{H}, \mathrm{Ac}), 2.01-1.68\left(m, 6 \mathrm{H}, 16-\mathrm{H}_{\mathrm{a}}, 11-\mathrm{H}_{\mathrm{a}}, 11-\mathrm{H}_{\mathrm{b}}, 18-\mathrm{H}\right.$, $\left.22-\mathrm{H}_{\mathrm{a}}, 16-\mathrm{H}_{\mathrm{b}}\right), 1.68-1.19\left(m, 13 \mathrm{H}, 15-\mathrm{H}_{\mathrm{a}}, 1-\mathrm{H}_{\mathrm{a}}, 2-\mathrm{H}_{\mathrm{a}}, 2-\mathrm{H}_{\mathrm{b}}, 9-\mathrm{H}, 6-\mathrm{H}_{\mathrm{a}}, 21-\mathrm{H}_{\mathrm{a}}, 7-\mathrm{H}_{\mathrm{a}}, 22-\mathrm{H}_{\mathrm{b}}, 19-\mathrm{H}, 6-\mathrm{H}_{\mathrm{b}}\right.$, 
21- $\left.\mathrm{H}_{\mathrm{b}}, 7-\mathrm{H}_{\mathrm{b}}\right), 1.07(\mathrm{~s}, 3 \mathrm{H}, 27-\mathrm{H}), 1.06-0.94\left(m, 3 \mathrm{H}, 1-\mathrm{H}_{\mathrm{b}}, 15-\mathrm{H}_{\mathrm{b}}, 20-\mathrm{H}\right), 0.94(d, J=6.5 \mathrm{~Hz}, 3 \mathrm{H}, 30-\mathrm{H})$, $0.92(s, 3 \mathrm{H}, 25-\mathrm{H}), 0.87(d, J=6.5 \mathrm{~Hz}, 3 \mathrm{H}, 29-\mathrm{H}), 0.85(s, 3 \mathrm{H}, 23-\mathrm{H}), 0.83(\mathrm{~s}, 3 \mathrm{H}, 24-\mathrm{H}), 0.82-0.78(m, 1 \mathrm{H}$, 5-H), $0.76(\mathrm{~s}, 3 \mathrm{H}, 26-\mathrm{H}) \mathrm{ppm} ;{ }^{13} \mathrm{C} \mathrm{NMR}\left(101 \mathrm{MHz}, \mathrm{CDCl}_{3}\right): \delta=178.0(\mathrm{C}-28), 173.4(2 \times \mathrm{CO}$, acetate), 173.3 (CO, acetate), 171.1 (Ac), 170.0 (C-35), 139.8 (C-13), $131.9(2 \times \mathrm{CH}$, allyl), $131.7(\mathrm{CH}$, allyl), 125.4 (C-12), $119.0\left(\mathrm{CH}_{2}\right.$, allyl), $118.8\left(2 \times \mathrm{CH}_{2}\right.$, allyl $), 80.9(\mathrm{C}-3), 66.0\left(\mathrm{CH}_{2}\right.$, allyl $), 65.9\left(2 \times \mathrm{CH}_{2}\right.$, allyl $), 56.8$ (C-32), 55.4 (C-36), 55.3 (C-5), $55.2\left(3 \times \mathrm{CH}_{2}\right.$, acetate), 53.9 (C-18), $53.6\left(8 \times \mathrm{CH}_{2}\right.$, cyclen), 52.7 (C-33, C-33'), 47.9 (C-17), 47.5 (C-9), 45.0 (C-34, C-34'), 42.6 (C-24), 39.8 (C-19), 39.7 (C-8), 39.1 (C-20), 38.4 (C-1), 37.8 (C-4), 37.4 (C-22), 37.0 (C-10), 35.9 (C-31), 32.8 (C-7), 31.0 (C-21), 28.2 (C-23), 27.9 (C-15), 24.9 (C-16), 23.6 (C-2), 23.6 (C-11), 23.3 (C-27), 21.4 (Ac), 21.3 (C-30), 18.3 (C-6), 17.4 (C-29), 17.1 (C-26), 16.8 (C-24), 15.7 (C-25) ppm; MS (ESI, MeOH): $m / z=569.8\left(100 \%\right.$, $\left.\left.[\mathrm{M}+\mathrm{Na}+\mathrm{H}]^{+}\right), 1138.8(52 \% \text {, [M + Na }]^{+}\right)$; analysis calcd for $\mathrm{C}_{63} \mathrm{H}_{101} \mathrm{~N}_{7} \mathrm{O}_{10}$ (1116.54): $\mathrm{C}$ 67.77, $\mathrm{H}$ 9.12, $\mathrm{N}$ 8.78; found: $\mathrm{C} 67.50, \mathrm{H}$ 9.37, $\mathrm{N}$ 8.43.

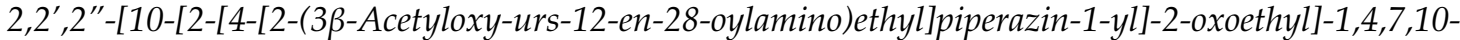

tetraazacyclododecane-1,4,7-triyl]triacetic acid (15). Triphenylphosphane $(0.038 \mathrm{mmol}),\left[\left(\mathrm{PPh}_{3}\right)_{4} \mathrm{Pd}\right]$ $(0.013 \mathrm{mmol})$ and pyrrolidine $(0.290 \mathrm{mmol})$ were added to a solution of compound $14(0.128 \mathrm{mmol})$ in acetonitrile $(4 \mathrm{~mL})$, and the mixture was stirred for 6 days at $25^{\circ} \mathrm{C}$. After filtration, the solvent was removed under reduced pressure, and the crude product was subjected to column chromatography (RP18, MeCN/MeOH/TFA 60:40:0.1) affording compound 15 as colorless solid (96\%); m.p. 206-210 ${ }^{\circ} \mathrm{C}$ (decomp.); $[\alpha]_{\mathrm{D}}=+17.1^{\circ}$ (c 0.315, MeOH); $\mathrm{R}_{\mathrm{f}}=0.35$ (RP18, ACN/TFA 100:1); IR (ATR): $v=2925 w, 1634 \mathrm{~s}$, $1371 m, 1245 s, 1199 s, 1127 s, 1026 m, 829 m, 800 m, 719 m \mathrm{~cm}^{-1} ;{ }^{1} \mathrm{H}$ NMR $\left(400 \mathrm{MHz}, \mathrm{CD}_{3} \mathrm{OD}\right): \delta=5.35$ $(t, J=3.6 \mathrm{~Hz}, 1 \mathrm{H}, 12-\mathrm{H}), 4.47(d d, J=11.0,5.3 \mathrm{~Hz}, 1 \mathrm{H}, 3-\mathrm{H}), 3.72-2.93\left(m, 14 \mathrm{H}, 34-\mathrm{H}, 34^{\prime}-\mathrm{H}, 36-\mathrm{H}, 31-\mathrm{H}_{\mathrm{a}}\right.$, $31-\mathrm{H}_{\mathrm{b}}, 3 \times \mathrm{CH}_{2}$ (acetate)), 2.91-2.20 (m, 22H, 32- $\mathrm{H}, 33-\mathrm{H}, 33^{\prime}-\mathrm{H}, 8 \times \mathrm{CH}_{2}$ (cyclen)), 2.09-2.06 $(m, 1 \mathrm{H}$, 18-H), $2.03(\mathrm{~s}, 3 \mathrm{H}, \mathrm{Ac}), 2.02-1.93\left(m, 3 \mathrm{H}, 11-\mathrm{H}_{\mathrm{a}}, 11-\mathrm{H}_{\mathrm{b}}, 16-\mathrm{H}_{\mathrm{a}}\right), 1.84-1.23\left(m, 15 \mathrm{H}, 15-\mathrm{H}_{\mathrm{a}}, 22-\mathrm{H}_{\mathrm{a}}, 1-\mathrm{H}_{\mathrm{a}}\right.$, $\left.16-\mathrm{H}_{\mathrm{b}}, 2-\mathrm{H}_{\mathrm{a}}, 2-\mathrm{H}_{\mathrm{b}}, 9-\mathrm{H}, 7-\mathrm{H}_{\mathrm{a}}, 6-\mathrm{H}_{\mathrm{a}}, 21-\mathrm{H}_{\mathrm{a}}, 22-\mathrm{H}_{\mathrm{b}}, 19-\mathrm{H}, 6-\mathrm{H}_{\mathrm{b}}, 21-\mathrm{H}_{\mathrm{b}}, 7-\mathrm{H}_{\mathrm{b}}\right), 1.15(\mathrm{~s}, 3 \mathrm{H}, 27-\mathrm{H}), 1.12-0.96$ $\left(m, 3 \mathrm{H}, 15-\mathrm{H}_{\mathrm{b}}, 1-\mathrm{H}_{\mathrm{b}}, 20-\mathrm{H}\right), 0.99(\mathrm{~s}, 3 \mathrm{H}, 25-\mathrm{H}), 0.97(b r s, 3 \mathrm{H}, 30-\mathrm{H}), 0.92(d, J=6.4 \mathrm{~Hz}, 3 \mathrm{H}, 29-\mathrm{H}), 0.89$ (s, 3H, 24-H), $0.88(s, 3 \mathrm{H}, 23-\mathrm{H}), 0.87-0.84(\mathrm{~m}, 1 \mathrm{H}, 5-\mathrm{H}), 0.83(\mathrm{~s}, 3 \mathrm{H}, 26-\mathrm{H}) \mathrm{ppm} ;{ }^{13} \mathrm{C}$ NMR $(101 \mathrm{MHz}$, $\left.\mathrm{CD}_{3} \mathrm{OD}\right): \delta=180.1$ (C-28), $172.8(\mathrm{Ac}), 172.5$ (CO, acetate), $172.1(2 \times \mathrm{CO}$, acetate), $171.2(\mathrm{C}-35), 140.2$ (C-13), $127.0(\mathrm{C}-12), 82.4(\mathrm{C}-3), 59.8\left(\mathrm{CH}_{2}\right.$, acetate), $59.7\left(\mathrm{CH}_{2}\right.$, acetate $), 59.1\left(\mathrm{CH}_{2}\right.$, acetate), $57.7(\mathrm{C}-32)$, 56.7 (C-5), 55.3 (C-36), 54.4 (C-18), 54.2 (8 $\times \mathrm{CH}_{2}$, cyclen), 53.8 (C-33, C-33'), 49.0 (C-17), 48.8 (C-9), 46.2 (C-34. C-34'), 43.4 (C-14), 40.9 (C-8), 40.9 (C-19), 40.3 (C-20), 39.4 (C-1), 38.7 (C-4), 38.7 (C-22), 38.1 (C-10), 37.3 (C-31), 34.0 (C-7), 31.9 (C-21), 29.0 (C-15), 28.6 (C-23), 25.4 (C-16), 24.6 (C-2), 24.5 (C-11), 24.0 (C-27), 21.6 (C-30), 21.1 (Ac), 19.3 (C-6), 18.0 (C-26), 17.8 (C-29), 17.2 (C-24), 16.1 (C-25) ppm; MS (ESI, MeOH, positive ion mode): $m / z=1018.6\left(27 \%\right.$, $\left.[\mathrm{M}+\mathrm{Na}]^{+}\right), 1034.7\left(100 \%,[\mathrm{M}+\mathrm{K}]^{+}\right)$; MS (ESI, $\mathrm{MeOH}$, negative ion mode): $\mathrm{m} / \mathrm{z}=1017.7\left(13 \%,[\mathrm{M}-2 \mathrm{H}+\mathrm{Na}]^{-}\right), 1032.6\left(100 \%,\left[\mathrm{M}-2 \mathrm{H}+\mathrm{K}^{-}\right)\right.$; analysis calcd for $\mathrm{C}_{54} \mathrm{H}_{89} \mathrm{~N}_{7} \mathrm{O}_{10}$ (996.35): C 65.10, $\mathrm{H}$ 9.00, $\mathrm{N}$ 9.84; found: $\mathrm{C} 64.82, \mathrm{H} 9.21, \mathrm{~N} 9.61$.

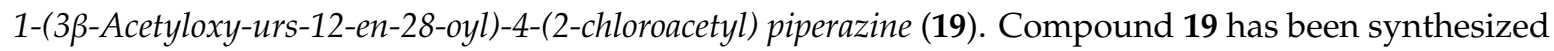
from 16 according to general procedure $\mathrm{C}$. Column chromatography $\left(\mathrm{SiO}_{2}, \mathrm{CHCl}_{3} /\right.$ acetone/hexanes 95:5:20) furnished compound 19 (94\%); m.p. $155-158^{\circ} \mathrm{C} ;[\alpha]_{\mathrm{D}}=+34.3^{\circ}\left(\mathrm{c} 0.370, \mathrm{CHCl}_{3}\right) ; \mathrm{R}_{\mathrm{f}}=0.66$ $\left(\mathrm{CHCl}_{3}\right.$ /acetone 9:1); IR (ATR): $v=2924 m, 2871 w, 1731 m, 1658 s, 1455 m, 1392 m, 1370 m, 1243 s, 1200 m$, $1145 m, 1025 m, 985 m, 752 m \mathrm{~cm}^{-1} ;{ }^{1} \mathrm{H}$ NMR $\left(400 \mathrm{MHz} \mathrm{CDCl}_{3}\right): \delta=5.21(t, J=3.6 \mathrm{~Hz}, 1 \mathrm{H}, 12-\mathrm{H})$, 4.52-4.45 (m, 1H, 3-H), $4.06(\mathrm{~s}, 2 \mathrm{H}, 34-\mathrm{H}), 3.73-3.46\left(m, 8 \mathrm{H}, 31-\mathrm{H}, 31^{\prime}-\mathrm{H}, 32-\mathrm{H}, 32^{\prime}-\mathrm{H}\right), 2.41(d, J=11.6$ $\mathrm{Hz}, 1 \mathrm{H}, 18-\mathrm{H}), 2.24-2.11\left(m, 1 \mathrm{H}, 16-\mathrm{H}_{\mathrm{a}}\right), 2.03(\mathrm{~s}, 3 \mathrm{H}, \mathrm{Ac}), 1.91\left(d d, J=8.9,3.6 \mathrm{~Hz}, 2 \mathrm{H}, 11-\mathrm{H}_{\mathrm{a}}, 11-\mathrm{H}_{\mathrm{b}}\right)$, 1.80-1.24 (m, 15H, 15- $\mathrm{H}_{\mathrm{a}}, 16-\mathrm{H}_{\mathrm{b}}, 22-\mathrm{H}_{\mathrm{a}}, 1-\mathrm{H}_{\mathrm{a}}, 2-\mathrm{H}_{\mathrm{a}}, 2-\mathrm{H}_{\mathrm{b}}, 22-\mathrm{H}_{\mathrm{b}}, 9-\mathrm{H}, 6-\mathrm{H}_{\mathrm{a}}, 21-\mathrm{H}_{\mathrm{a}}, 7-\mathrm{H}_{\mathrm{a}}, 19-\mathrm{H}, 6-\mathrm{H}_{\mathrm{b}}$, $\left.21-\mathrm{H}_{\mathrm{b}}, 7-\mathrm{H}_{\mathrm{b}}\right), 1.07(\mathrm{~s}, 3 \mathrm{H}, 27-\mathrm{H}), 1.12-0.98\left(m, 3 \mathrm{H}, 1-\mathrm{H}_{\mathrm{b}}, 15-\mathrm{H}_{\mathrm{b}}, 20-\mathrm{H}\right), 0.95(d, J=6.2 \mathrm{~Hz}, 3 \mathrm{H}, 30-\mathrm{H})$, $0.93(s, 3 \mathrm{H}, 25-\mathrm{H}), 0.88(d, J=6.4 \mathrm{~Hz}, 3 \mathrm{H}, 29-\mathrm{H}), 0.85(s, 3 \mathrm{H}, 23-\mathrm{H}), 0.84(s, 3 \mathrm{H}, 24-\mathrm{H}), 0.84-0.77(m, 1 \mathrm{H}$, 5-H), $0.73(\mathrm{~s}, 3 \mathrm{H}, 26-\mathrm{H}) \mathrm{ppm} ;{ }^{13} \mathrm{C}$ NMR $\left(101 \mathrm{MHz}, \mathrm{CDCl}_{3}\right): \delta=175.8$ (C-28), 171.1 (Ac), 165.5 (C-33), 138.6 (C-13), 125.5 (C-12), 81.0 (C-3), 55.5 (C-5), 55.1 (C-18), 48.8 (C-17), 47.7 (C-9), 46.3 (C-31), 45.5 (C-31') 45.1 (C-32), 42.3 (C-32' , C-14), 40.9 (C-34), 39.6 (C-19), 39.6 (C-8), 38.9 (C-20), 38.4 (C-1), 37.8 (C-4), 37.1 (C-10), 34.6 (C-22), 33.1 (C-7), 30.6 (C-21), 28.3 (C-15), 28.2 (C-23), 23.9 (C-27), 23.7 (C-2, C-16), 23.4 (C-11), 21.4 (Ac), 21.4 (C-30), 18.3 (C-6), 17.6 (C-29), 17.0 (C-26), 16.9 (C-24), 15.6 (C-25) ppm; MS 
(ESI, MeOH): $\left.m / z=643.5\left(100 \%,[\mathrm{M}+\mathrm{H}]^{+}\right), 665.4\left(56 \%,[\mathrm{M}+\mathrm{Na}]^{+}\right), 1307.378 \%,[2 \mathrm{M}+\mathrm{Na}]^{+}\right)$; analysis calcd for $\mathrm{C}_{38} \mathrm{H}_{59} \mathrm{ClN}_{2} \mathrm{O}_{4}$ (643.4): C 70.94, $\mathrm{H}$ 9.24, $\mathrm{N}$ 4.35; found: C 70.72, $\mathrm{H}$ 9.51, $\mathrm{N}$ 4.09.

(3ß) N-(2-(2-Chloroacetyl)aminoethyl)-3-acetyloxy-urs-12-en-28-amide (20). Compound 20 was synthesized from 17 according to general procedure $\mathrm{C}$. Column chromatography $\left(\mathrm{SiO}_{2}, \mathrm{CHCl}_{3} /\right.$ acetone/hexanes 95:5:20) furnished compound 20 (91\%); m.p. $103-107^{\circ} \mathrm{C} ;[\alpha]_{\mathrm{D}}=+25.2^{\circ}\left(c 0.300, \mathrm{CHCl}_{3}\right) ; \mathrm{R}_{\mathrm{f}}=0.40$ $\left(\mathrm{CHCl}_{3}\right.$ /acetone 9:1); IR (KBr): $v=3422 \mathrm{br} s, 2948 \mathrm{~s}, 2872 \mathrm{~m}, 1734 \mathrm{~s}, 1640 \mathrm{~s}, 1532 \mathrm{~s}, 1456 \mathrm{~m}, 1370 \mathrm{~m}, 1246 \mathrm{~s}$, $1148 w, 1092 w, 1028 m, 756 \mathrm{~m} \mathrm{~cm}^{-1},{ }^{1} \mathrm{H}$ NMR $\left(400 \mathrm{MHz} \mathrm{CDCl}_{3}\right): \delta=7.43(t, J=5.1 \mathrm{~Hz}, 1 \mathrm{H}, \mathrm{NH}), 6.28$ $(t, J=5.7 \mathrm{~Hz}, 1 \mathrm{H}, \mathrm{NH}), 5.32(t, J=3.6 \mathrm{~Hz}, 1 \mathrm{H}, 12-\mathrm{H}), 4.48(d d, J=9.7,6.1 \mathrm{~Hz}, 1 \mathrm{H}, 3-\mathrm{H}), 4.00(s, 2 \mathrm{H}, 34-\mathrm{H})$, 3.56-3.46 (m, 1H, 31- $\left.\mathrm{H}_{\mathrm{a}}\right), 3.41-3.35(m, 2 \mathrm{H}, 32-\mathrm{H}), 3.26-3.18\left(m, 1 \mathrm{H}, 31-\mathrm{H}_{\mathrm{b}}\right), 2.04(\mathrm{~s}, 3 \mathrm{H}, \mathrm{Ac}), 2.03-1.80$ $\left(m, 5 \mathrm{H}, 16-\mathrm{H}_{\mathrm{a}}, 11-\mathrm{H}_{\mathrm{a}}, 11-\mathrm{H}_{\mathrm{b}}, 18-\mathrm{H}, 22-\mathrm{H}_{\mathrm{a}}\right), 1.80-1.22\left(m, 14 \mathrm{H}, 16-\mathrm{H}_{\mathrm{b}}, 2-\mathrm{H}_{\mathrm{a}}, 2-\mathrm{H}_{\mathrm{b}}, 1-\mathrm{H}_{\mathrm{a}}, 15-\mathrm{H}_{\mathrm{a}}, 9-\mathrm{H}, 6-\mathrm{H}_{\mathrm{a}}\right.$, $\left.21-\mathrm{H}_{\mathrm{a}}, 7-\mathrm{H}_{\mathrm{a}}, 22-\mathrm{H}_{\mathrm{b}}, 19-\mathrm{H}, 6-\mathrm{H}_{\mathrm{b}}, 21-\mathrm{H}_{\mathrm{b}}, 7-\mathrm{H}_{\mathrm{b}}\right), 1.08(\mathrm{~s}, 3 \mathrm{H}, 27-\mathrm{H}), 1.08-0.95\left(\mathrm{~m}, 3 \mathrm{H}, 1-\mathrm{H}_{\mathrm{b}}, 15-\mathrm{H}_{\mathrm{b}}, 20-\mathrm{H}\right)$, $0.94(s, 3 \mathrm{H}, 30-\mathrm{H}), 0.93(s, 3 \mathrm{H}, 25-\mathrm{H}), 0.87(d, J=6.5 \mathrm{~Hz}, 3 \mathrm{H}, 29-\mathrm{H}), 0.86(s, 3 \mathrm{H}, 23-\mathrm{H}), 0.84(s, 3 \mathrm{H}, 24-\mathrm{H})$, 0.84-0.79 (m, 1H, 5-H), $0.75(\mathrm{~s}, 3 \mathrm{H}, 26-\mathrm{H}) \mathrm{ppm} ;{ }^{13} \mathrm{C} \mathrm{NMR}\left(101 \mathrm{MHz}, \mathrm{CDCl}_{3}\right): \delta=180.0(\mathrm{C}-28), 171.1$ (Ac), 167.0 (C-33), 139.7 (C-13), 125.9 (C-12), 81.0 (C-3), 55.4 (C-5), 53.8 (C-18), 48.0 (C-17), 47.6 (C-9), 42.6 (C-14), 42.6 (C-34), 41.3 (C-32), 39.9 (C-19), 39.7 (C-8), 39.2 (C-31), 39.2 (C-20), 38.4 (C-1), 37.8 (C-4), 37.4 (C-22), 37.0 (C-10), 32.8 (C-7), 31.0 (C-21), 28.2 (C-23), 27.9 (C-15), 24.9 (C-16), 23.7 (C-2), 23.5 (C-11), 23.4 (C-27), 21.4 (Ac), 21.3 (C-30), 18.3 (C-6), 17.4 (C-29), 17.0 (C-26), 16.8 (C-24), 15.7 (C-25) ppm; MS (ESI, $\mathrm{MeOH}): m / z=617.3\left(48 \%,[\mathrm{M}+\mathrm{H}]^{+}\right), 639.5\left(52 \%,[\mathrm{M}+\mathrm{Na}]^{+}\right), 1255.4\left(100 \%,[2 \mathrm{M}+\mathrm{Na}]^{+}\right) ;$analysis calcd for $\mathrm{C}_{36} \mathrm{H}_{57} \mathrm{ClN}_{2} \mathrm{O}_{4}$ (617.31): C 70.04, $\mathrm{H}$ 9.31, N 4.54; found: C 69.83, H 9.52, N 4.11.

(3ß) N-(2-(2-(2-Chloroacetyl)aminoethoxy)ethyl)-3-acetyloxy-urs-12-en-28-amide (21). Compound 21 has been synthesized from 18 according to general procedure $\mathrm{C}$. Column chromatography $\left(\mathrm{SiO}_{2}, \mathrm{CHCl}_{3} /\right.$ acetone/hexanes 95:5:20) furnished compound $21(91 \%) ;$ m.p. $94-97^{\circ} \mathrm{C} ;[\alpha]_{\mathrm{D}}=+33.7^{\circ}$ ( c 0.335, $\left.\mathrm{CHCl}_{3}\right) ; \mathrm{R}_{\mathrm{f}}=0.35\left(\mathrm{CHCl}_{3} /\right.$ acetone 9:1); IR (KBr): $v=3426 b r \mathrm{~s}, 2928 m, 2872 \mathrm{~m}, 1734 \mathrm{~m}, 1638 \mathrm{~s}$, $1528 m, 1458 w, 1386 w, 1248 s, 1124 w, 1028 \mathrm{~m} \mathrm{~cm}^{-1} ;{ }^{1} \mathrm{H}$ NMR $\left(400 \mathrm{MHz}, \mathrm{CDCl}_{3}\right): \delta=7.00-6.90(m, 1 \mathrm{H}$, $\mathrm{NH}), 6.22(t, J=5.0 \mathrm{~Hz}, 1 \mathrm{H}, \mathrm{NH}), 5.30(t, J=3.6 \mathrm{~Hz}, 1 \mathrm{H}, 12-\mathrm{H}), 4.49(d d, J=10.0,5.7 \mathrm{~Hz}, 1 \mathrm{H}, 3-\mathrm{H})$, $4.06(s, 2 \mathrm{H}, 36-\mathrm{H}), 3.57-3.47\left(m, 7 \mathrm{H}, 32-\mathrm{H}, 31-\mathrm{H}_{\mathrm{a}}, 33-\mathrm{H}, 34-\mathrm{H}\right), 3.31-3.21\left(m, 1 \mathrm{H}, 31-\mathrm{H}_{\mathrm{b}}\right), 2.04(\mathrm{~s}, 3 \mathrm{H}$, Ac), 2.02-1.76 (m, 5H, 16- $\left.\mathrm{H}_{\mathrm{a}}, 11-\mathrm{H}_{\mathrm{a}}, 11-\mathrm{H}_{\mathrm{b}}, 18-\mathrm{H}, 22-\mathrm{H}_{\mathrm{a}}\right), 1.77-1.21\left(m, 14 \mathrm{H}, 16-\mathrm{H}_{\mathrm{b}}, 15-\mathrm{H}_{\mathrm{a}}, 1-\mathrm{H}_{\mathrm{a}}, 2-\mathrm{H}_{\mathrm{a}}\right.$, $\left.2-\mathrm{H}_{\mathrm{b}}, 9-\mathrm{H}, 6-\mathrm{H}_{\mathrm{a}}, 21-\mathrm{H}_{\mathrm{a}}, 7-\mathrm{H}_{\mathrm{a}}, 22-\mathrm{H}_{\mathrm{b}}, 19-\mathrm{H}, 6-\mathrm{H}_{\mathrm{b}}, 21-\mathrm{H}_{\mathrm{b}}, 7-\mathrm{H}_{\mathrm{b}}\right), 1.09(\mathrm{~s}, 3 \mathrm{H}, 27-\mathrm{H}), 1.08-0.95(m, 3 \mathrm{H}$, $\left.1-\mathrm{H}_{\mathrm{b}}, 15-\mathrm{H}_{\mathrm{b}}, 20-\mathrm{H}\right), 0.94(d, J=6.2 \mathrm{~Hz}, 3 \mathrm{H}, 30-\mathrm{H}), 0.93(s, 3 \mathrm{H}, 25-\mathrm{H}), 0.88(d, J=6.2 \mathrm{~Hz}, 3 \mathrm{H}, 29-\mathrm{H}), 0.86$ $(s, 3 \mathrm{H}, 23-\mathrm{H}), 0.85(\mathrm{~s}, 3 \mathrm{H}, 24-\mathrm{H}), 0.84-0.80(\mathrm{~m}, 1 \mathrm{H}, 5-\mathrm{H}), 0.78(\mathrm{~s}, 3 \mathrm{H}, 26-\mathrm{H}) \mathrm{ppm} ;{ }^{13} \mathrm{C}$ NMR $(101 \mathrm{MHz}$, $\left.\mathrm{CDCl}_{3}\right): \delta=178.4(\mathrm{C}-28), 171.1$ (Ac), 166.1 (C-35), 139.9 (C-13), 125.6 (C-12), 80.9 (C-3), 70.0 (C-33), 69.4 (C-32), 55.4 (C-5), 54.0 (C-18), 48.0 (C-17), 47.6 (C-9), 42.8 (C-36), 42.6 (C-14), 39.9 (C-29), 39.8 (C-34), 39.7 (C-8), 39.2 (C-31), 39.2 (C-20), 38.5 (C-1), 37.8 (C-4), 37.4 (C-22), 37.0 (C-10), 32.8 (C-7), 31.0 (C-21), 28.2 (C-23), 28.0 (C-15), 25.0 (C-16), 23.7 (C-2), 23.6 (C-11), 23.4 (C-27), 21.4 (Ac), 21.4 (C-30), 18.3 (C-6), 17.4 (C-29), 17.1 (C-26), 16.9 (C-24), 15.7 (C-25) ppm; MS (ESI, MeOH): $m / z=661.4\left(60 \%,\left[\mathrm{M}+\mathrm{H}^{+}\right)\right.$, $685.5\left(86 \%,[\mathrm{M}+\mathrm{Na}]^{+}\right), 1343.3\left(100 \%,[2 \mathrm{M}+\mathrm{Na}]^{+}\right)$; analysis calcd for $\mathrm{C}_{38} \mathrm{H}_{61} \mathrm{ClN}_{2} \mathrm{O}_{5}$ (661.37): $\mathrm{C} 69.01$, H 9.30, N 4.24, Cl 5.36; found: C 68.80, H 9.61, N 4.01.

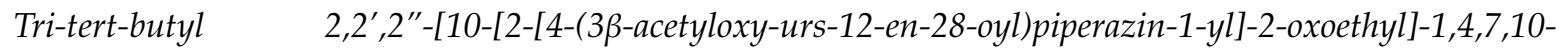
tetraazacyclododecane-1,4,7-triyl]triacetate (22). Compound 22 was synthesized from 6 and 19 according to general procedure D. Column chromatography $\left(\mathrm{SiO}_{2}, \mathrm{CHCl}_{3} / \mathrm{MeOH} 95: 5\right)$ furnished compound $22(88 \%)$; m.p. $237-240{ }^{\circ} \mathrm{C}$ (decomp.); $[\alpha]_{\mathrm{D}}=+15.0^{\circ}\left(\mathrm{c} 0.3, \mathrm{CHCl}_{3}\right) ; \mathrm{R}_{\mathrm{f}}=0.42\left(\mathrm{CHCl}_{3} / \mathrm{MeOH}\right.$ 9:1); IR (ATR): $v=2927 w, 2928 w, 2871 w, 2829 w, 1726 s, 1646 m, 1453 m, 1424 w, 1368 s, 1305 m, 1227 s$, $1160 \mathrm{~s}, 1105 \mathrm{~s}, 1004 \mathrm{~m}, 975 \mathrm{~m}, 754 \mathrm{~m} \mathrm{~cm}^{-1}{ }^{1} \mathrm{H}$ NMR $\left(400 \mathrm{MHz}, \mathrm{CDCl}_{3}\right): \delta=5.19(t, J=3.5 \mathrm{~Hz}, 1 \mathrm{H}, 12-\mathrm{H})$, $4.47(d d, J=9.8,6.0 \mathrm{~Hz}, 1 \mathrm{H}, 3-\mathrm{H}), 3.93-2.05\left(m, 32 \mathrm{H}, 31-\mathrm{H}, 31^{\prime}-\mathrm{H}, 32-\mathrm{H}, 32^{\prime}-\mathrm{H}, 8 \times \mathrm{CH}_{2}\right.$ (cyclen), $3 \times \mathrm{CH}_{2}$ (acetate), 34-H), $2.40(d, J=11.0 \mathrm{~Hz}, 1 \mathrm{H}, 18-\mathrm{H}), 2.19-2.09\left(m, 1 \mathrm{H}, 16-\mathrm{H}_{\mathrm{a}}\right), 2.02(\mathrm{~s}, 3 \mathrm{H}, \mathrm{Ac})$, $1.93-1.85\left(m, 2 \mathrm{H}, 11-\mathrm{H}_{\mathrm{a}}, 11-\mathrm{H}_{\mathrm{b}}\right), 1.82-1.67\left(m, 3 \mathrm{H}, 15-\mathrm{H}_{\mathrm{a}}, 16-\mathrm{H}_{\mathrm{b}}, 22-\mathrm{H}_{\mathrm{a}}\right), 1.65-1.21\left(m, 12 \mathrm{H}, 2-\mathrm{H}_{\mathrm{a}}, 2-\mathrm{H}_{\mathrm{b}}\right.$, 22- $\left.\mathrm{H}_{\mathrm{b}}, 1-\mathrm{H}_{\mathrm{a}}, 9-\mathrm{H}, 21-\mathrm{H}_{\mathrm{a}}, 6-\mathrm{H}_{\mathrm{a}}, 7-\mathrm{H}_{\mathrm{a}}, 19-\mathrm{H}, 21-\mathrm{H}_{\mathrm{b}}, 6-\mathrm{H}_{\mathrm{b}}, 7-\mathrm{H}_{\mathrm{b}}\right), 1.43\left(s, 9 \mathrm{H}, \mathrm{CH}_{3}(t\right.$ Butyl) $), 1.42(s, 9 \mathrm{H}$; $\mathrm{CH}_{3}$ (tButyl)), $1.42\left(s, 9 \mathrm{H}, \mathrm{CH}_{3}\right.$ (tButyl)), 1.10-0.96 (m, 3H, 1- $\left.\mathrm{H}_{\mathrm{b}}, 15-\mathrm{H}_{\mathrm{b}}, 20-\mathrm{H}\right), 1.05(s, 3 \mathrm{H}, 27-\mathrm{H})$, $0.92(d, J=6.3 \mathrm{~Hz}, 3 \mathrm{H}, 30-\mathrm{H}), 0.91(s, 3 \mathrm{H}, 25-\mathrm{H}), 0.86(d, J=6.3 \mathrm{~Hz}, 3 \mathrm{H}, 29-\mathrm{H}), 0.84(s, 3 \mathrm{H}, 23-\mathrm{H}), 0.82$ 
$(\mathrm{s}, 3 \mathrm{H}, 24-\mathrm{H}), 0.82-0.76(\mathrm{~m}, 1 \mathrm{H}, 5-\mathrm{H}), 0.71(\mathrm{~s}, 3 \mathrm{H}, 26-\mathrm{H}) \mathrm{ppm} ;{ }^{13} \mathrm{C} \mathrm{NMR}\left(101 \mathrm{MHz}, \mathrm{CDCl}_{3}\right): \delta=175.9$ (C-28), 172.8 (CO, acetate), 172.7 (CO, acetate), 171.0 (Ac), 170.7 (C-33), 138.7 (C-13), 125.1 (C-12), 81.9 ( $\mathrm{C}_{\mathrm{q}}$, tButyl), $81.7\left(\mathrm{C}_{\mathrm{q}}\right.$, tButyl), $81.7\left(\mathrm{C}_{\mathrm{q}}\right.$, tButyl), $81.0(\mathrm{C}-3), 55.8\left(\mathrm{CH}_{2}\right.$, acetate), $55.8\left(\mathrm{CH}_{2}\right.$, acetate), 55.7 ( $\mathrm{CH}_{2}$, cyclen), 55.4 (C-5), 55.1 (C-18), 48.8 (C-17), 47.6 (C-9), 44.6 (C-31, C-31', C-32, C-32'), 42.3 (C-14), 41.7 (C-34), 39.5 (C-8), 39.4 (C-19), 38.8 (C-20), 38.3 (C-1), 37.8 (C-4), 37.0 (C-10), 34.4 (C-22), 33.1 (C-7), 30.5 (C-21), 28.3 (C-15), 28.2 (C-23), 28.1 ( $\left.\mathrm{CH}_{3}, t \mathrm{Butyl}\right), 28.0\left(\mathrm{CH}_{3}, t \mathrm{Butyl}\right), 23.8$ (C-27), 23.6 (C-2, C-16), 23.4 (C-11), 21.4 (Ac), 21.3 (C-30), 18.2 (C-6), 17.5 (C-29), 17.0 (C-26), 16.8 (C-24), 15.6 (C-25) ppm; MS (ESI, MeOH): $m / z=1143.7\left(100 \%\right.$, $\left.[\mathrm{M}+\mathrm{Na}]^{+}\right)$; analysis calcd for $\mathrm{C}_{64} \mathrm{H}_{108} \mathrm{~N}_{6} \mathrm{O}_{10}$ (1121.60): $\mathrm{C}$ 68.54, H 9.71, N 7.49; found: C 68.31, H 10.03, N 7.27.

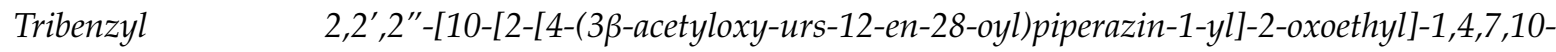
tetraazacyclododecane-1,4,7-triyl]triacetate (23). Compound 23 was synthesized from 19 and 7 according to general procedure $\mathrm{D}$. Column chromatography $\left(\mathrm{SiO}_{2}, \mathrm{CHCl}_{3} / \mathrm{MeOH} 95: 5\right)$ furnished compound 23 (72\%); m.p. $157-161{ }^{\circ} \mathrm{C} ;[\alpha]_{\mathrm{D}}=+4.2^{\circ}\left(\mathrm{c} 0.300, \mathrm{CHCl}_{3}\right) ; \mathrm{R}_{\mathrm{f}}=0.37\left(\mathrm{CHCl}_{3} / \mathrm{MeOH} 9: 1\right)$; IR (ATR): $v=2945 w, 2836 w, 1730 s, 1638 m, 1454 m, 1424 w, 1392 m, 1370 m, 1302 m, 1243 s, 1194 s, 1105 s$, $1005 \mathrm{~m}, 966 \mathrm{~m}, 743 \mathrm{~m}, 697 \mathrm{~s} \mathrm{~cm}{ }^{-1}$; UV-Vis $\left(\mathrm{CHCl}_{3}\right): \lambda_{\max }(\log \varepsilon)=246 \mathrm{~nm}(3.96), 294 \mathrm{~nm}(3.47), 364 \mathrm{~nm}$ (3.23); ${ }^{1} \mathrm{H}$ NMR $\left(400 \mathrm{MHz}, \mathrm{CDCl}_{3}\right): \delta=7.39-7.26(m, 15 \mathrm{H}, 15 \times \mathrm{CH}(\mathrm{Bn})), 5.33-4.97(m, 7 \mathrm{H}, 12-\mathrm{H}$, $\left.3 \times \mathrm{CH}_{2}(\mathrm{Bn})\right), 4.45(d d, \mathrm{~J}=10.1,5.9 \mathrm{~Hz}, 1 \mathrm{H}, 3-\mathrm{H}), 4.02-2.05\left(m, 34 \mathrm{H}, 31-\mathrm{H}, 31^{\prime}-\mathrm{H}, 32-\mathrm{H}, 32^{\prime}-\mathrm{H}, 8 \times \mathrm{CH}_{2}\right.$ (cyclen), $3 \times \mathrm{CH}_{2}$ (acetate), 34- $\left.\mathrm{H}, 16-\mathrm{H}_{\mathrm{a}}, 18-\mathrm{H}\right), 2.02(\mathrm{~s}, 3 \mathrm{H}, \mathrm{Ac}), 1.95-1.65\left(m, 5 \mathrm{H}, 11-\mathrm{H}_{\mathrm{a}}, 11-\mathrm{H}_{\mathrm{b}}, 15-\mathrm{H}_{\mathrm{a}}\right.$, $\left.16-\mathrm{H}_{\mathrm{b}}, 22-\mathrm{H}_{\mathrm{a}}\right), 1.65-1.09\left(m, 12 \mathrm{H}, 2-\mathrm{H}_{\mathrm{a}}, 2-\mathrm{H}_{\mathrm{b}}, 22-\mathrm{H}_{\mathrm{b}}, 1-\mathrm{H}_{\mathrm{a}}, 9-\mathrm{H}, 21-\mathrm{H}_{\mathrm{a}}, 6-\mathrm{H}_{\mathrm{a}}, 7-\mathrm{H}_{\mathrm{a}}, 19-\mathrm{H}, 21-\mathrm{H}_{\mathrm{b}}, 6-\mathrm{H}_{\mathrm{b}}\right.$, $\left.7-\mathrm{H}_{\mathrm{b}}\right), 1.03(\mathrm{~s}, 3 \mathrm{H}, 27-\mathrm{H}), 1.08-0.95\left(m, 3 \mathrm{H}, 1-\mathrm{H}_{\mathrm{b}}, 15-\mathrm{H}_{\mathrm{b}}, 20-\mathrm{H}\right), 0.93(d, J=6.0 \mathrm{~Hz}, 3 \mathrm{H}, 30-\mathrm{H}), 0.85$ $(d, J=6.3 \mathrm{~Hz}, 3 \mathrm{H}, 29-\mathrm{H}), 0.85(s, 3 \mathrm{H}, 25-\mathrm{H}), 0.82(s, 3 \mathrm{H}, 23-\mathrm{H}), 0.79(\mathrm{~s}, 3 \mathrm{H}, 24-\mathrm{H}), 0.79-0.71(m, 1 \mathrm{H}, 5-\mathrm{H})$, $0.66(\mathrm{~s}, 3 \mathrm{H}, 26-\mathrm{H}) \mathrm{ppm} ;{ }^{13} \mathrm{C} \mathrm{NMR}\left(101 \mathrm{MHz}, \mathrm{CDCl}_{3}\right): \delta=175.9$ (C-28), 173.6 (CO, acetate), 171.0 (Ac), 170.8 (C-33), 138.6 (C-13), $135.5\left(\mathrm{C}_{\mathrm{i}}, \mathrm{Bn}\right), 135.3\left(\mathrm{C}_{\mathrm{i}}, \mathrm{Bn}\right), 128.7(\mathrm{CH}, \mathrm{Bn}), 128.7(\mathrm{CH}, \mathrm{Bn}), 128.6(\mathrm{CH}, \mathrm{Bn})$, 128.6 (CH, Bn), 128.4 (CH, Bn), 128.4 (CH, Bn), $125.1(\mathrm{C}-12), 81.0(\mathrm{C}-3), 67.1\left(\mathrm{CH}_{2}, \mathrm{Bn}\right), 66.9\left(\mathrm{CH}_{2}, \mathrm{Bn}\right)$, $55.7\left(\mathrm{CH}_{2}\right.$, acetate), $55.4\left(\mathrm{CH}_{2}\right.$, cyclen), 55.2 (C-5), 55.1 (C-18), 48.7 (C-17), 47.6 (C-9), 44.8 (C-31, C-31', C-32, C-32'), 42.2 (C-14), 42.0 (C-34), 39.5 (C-19), 39.5 (C-8), 38.8 (C-20), 38.3 (C-1), 37.7 (C-4), 36.9 (C-10), 34.5 (C-22), 33.1 (C-7), 30.6 (C-21), 28.2 (C-15), 28.1 (C-23), 23.6 (C-2, C-16), 23.5 (C-27), 23.4 (C-11), 21.4 (Ac), 21.3 (C-30), 18.2 (C-6), 17.5 (C-29), 17.0 (C-26), 16.8 (C-24), 15.5 (C-25) ppm; MS (ESI, MeOH): $m / z=1245.8\left(100 \%\right.$, $\left.[\mathrm{M}+\mathrm{Na}]^{+}\right)$; analysis calcd for $\mathrm{C}_{73} \mathrm{H}_{102} \mathrm{~N}_{6} \mathrm{O}_{10}(1223.65): \mathrm{C} 71.65, \mathrm{H}$ 8.40, N 6.87; found: C 71.42, H 8.69, N 6.56.

Tri-tert-butyl 2,2',2"-[10-[2-[2-(3ß-acetyloxy-urs-12-en-28-oylamino)ethyl]amino-2-oxoethyl]-1,4,7,10tetraazacyclododecane-1,4,7-triylltriacetate (24). Compound $\mathbf{2 4}$ was synthesized from $\mathbf{2 0}$ and $\mathbf{6}$ according to general procedure $\mathrm{D}$. Column chromatography $\left(\mathrm{SiO}_{2}, \mathrm{CHCl}_{3} / \mathrm{MeOH} 95: 5\right)$ furnished compound 24 (73\%); m.p. $254-257^{\circ} \mathrm{C}$ (decomp.); $[\alpha]_{\mathrm{D}}=+33.8^{\circ}$ (c 0.300, $\left.\mathrm{CHCl}_{3}\right) ; \mathrm{R}_{\mathrm{f}}=0.40\left(\mathrm{CHCl}_{3} / \mathrm{MeOH} 9: 1\right)$; IR (KBr): $v=2971 m, 2929 m, 2829 w, 1727 s, 1668 m, 1520 m, 1454 m, 1426 w, 1368 s, 1307 m, 1228 s, 1159 s$, $1106 \mathrm{~s}, 1027 \mathrm{~m}, 1006 \mathrm{~m}, 975 \mathrm{~m}, 755 \mathrm{~m} \mathrm{~cm}^{-1},{ }^{1} \mathrm{H} \mathrm{NMR}\left(400 \mathrm{MHz}, \mathrm{CDCl}_{3}\right): \delta=8.03(\mathrm{~s}, 1 \mathrm{H}, \mathrm{NH}), 7.08(s, 1 \mathrm{H}$, $\mathrm{NH}), 5.46(t, J=3.4 \mathrm{~Hz}, 1 \mathrm{H}, 12-\mathrm{H}), 4.47(d d, J=9.8,6.1 \mathrm{~Hz}, 1 \mathrm{H}, 3-\mathrm{H}), 3.80-2.05(m, 28 \mathrm{H}, 31-\mathrm{H}, 32-\mathrm{H}$, 34- $\mathrm{H}, 3 \times \mathrm{CH}_{2}$ (acetate), $8 \times \mathrm{CH}_{2}$ (cyclen)), 2.44-2.38 (m, 1H, 18- $\left.\mathrm{H}\right), 2.02(\mathrm{~s}, 3 \mathrm{H}, \mathrm{Ac}), 2.00-1.67(\mathrm{~m}, 6 \mathrm{H}$, $\left.15-\mathrm{H}_{\mathrm{a}}, 11-\mathrm{H}_{\mathrm{a}}, 11-\mathrm{H}_{\mathrm{b}}, 16-\mathrm{H}_{\mathrm{a}}, 16-\mathrm{H}_{\mathrm{b}}, 22-\mathrm{H}_{\mathrm{a}}\right), 1.66-1.19\left(m, 12 \mathrm{H}, 1-\mathrm{H}_{\mathrm{a}}, 2-\mathrm{H}_{\mathrm{a}}, 2-\mathrm{H}_{\mathrm{b}}, 22-\mathrm{H}_{\mathrm{b}}, 9-\mathrm{H}, 6-\mathrm{H}_{\mathrm{a}}, 7-\mathrm{H}_{\mathrm{a}}\right.$, 21- $\left.\mathrm{H}_{\mathrm{a}}, 19-\mathrm{H}, 6-\mathrm{H}_{\mathrm{b}}, 21-\mathrm{H}_{\mathrm{b}}, 7-\mathrm{H}_{\mathrm{b}}\right), 1.44\left(s, 9 \mathrm{H}, \mathrm{CH}_{3}(t\right.$ Butyl) $), 1.43\left(s, 9 \mathrm{H}, \mathrm{CH}_{3}\left(t\right.\right.$ Butyl)), $1.43\left(s, 9 \mathrm{H}, \mathrm{CH}_{3}\right.$ (tButyl)), 1.15-0.98 (m, 3H, 20-H, 1- $\left.\mathrm{H}_{\mathrm{b}}, 15-\mathrm{H}_{\mathrm{b}}\right), 1.04(s, 3 \mathrm{H}, 27-\mathrm{H}), 0.91(s, 3 \mathrm{H}, 25-\mathrm{H}), 0.90(d, J=6.1 \mathrm{~Hz}$, $3 \mathrm{H}, 30-\mathrm{H}), 0.88(d, J=6.1 \mathrm{~Hz}, 3 \mathrm{H}, 29-\mathrm{H}), 0.84(\mathrm{~s}, 3 \mathrm{H}, 23-\mathrm{H}), 0.83(\mathrm{~s}, 3 \mathrm{H}, 24-\mathrm{H}), 0.82-0.77(m, 1 \mathrm{H}, 5-\mathrm{H})$, $0.74(\mathrm{~s}, 3 \mathrm{H}, 26-\mathrm{H}) \mathrm{ppm} ;{ }^{13} \mathrm{C}$ NMR $\left(101 \mathrm{MHz}, \mathrm{CDCl}_{3}\right): \delta=178.7$ (C-28), 172.4 (CO, acetate), 171.7 (C-33), 171.1 (Ac), 139.0 (C-13), 125.5 (C-12), 82.1 (C $\mathrm{C}_{\mathrm{q}}$, tButyl), 82.1 ( $\mathrm{C}_{\mathrm{q}}$, tButyl), 82.1 ( $\mathrm{C}_{\mathrm{q}}$, tButyl), 81.1 (C-3), $56.4\left(3 \times \mathrm{CH}_{2}\right.$, acetate), $55.8(\mathrm{C}-34), 55.8\left(\mathrm{CH}_{2}\right.$, cyclen), $55.4(\mathrm{C}-5), 52.3(\mathrm{C}-18), 47.7(\mathrm{C}-9), 47.6(\mathrm{C}-17)$, 42.2 (C-14), 40.0 (C-32), 39.7 (C-19), 39.7 (C-8), 38.5 (C-20), 38.4 (C-31, C-1), 37.8 (C-4), 37.4 (C-22), 37.0 (C-10), 32.9 (C-7), 31.2 (C-21), 28.2 (C-23), $28.2\left(\mathrm{CH}_{3}, t\right.$ Butyl), $28.1\left(\mathrm{CH}_{3}, t \mathrm{Butyl}\right), 28.1\left(\mathrm{CH}_{3}, t\right.$ Butyl), 27.9 (C-15), 24.4 (C-16), 23.7 (C-2), 23.5 (C-27), 23.4 (C-11), 21.5 (C-30), 21.4 (Ac), 18.4 (C-6), 17.2 (C-29), 17.0 
(C-26), 16.9 (C-24), 15.7 (C-25) ppm; MS (ESI, MeOH): $\left.\mathrm{m} / z=1117.7(100 \% \text {, [M + Na }]^{+}\right)$; analysis calcd for $\mathrm{C}_{62} \mathrm{H}_{106} \mathrm{~N}_{6} \mathrm{O}_{10}$ (1095.56): C 67.97, H 9.75, N 7.67; found: C 67.68, H 10.02, N 7.41.

Tribenzyl 2,2',2"-[10-[2-[2-(3ß-acetyloxy-urs-12-en-28-oylamino)ethyl]amino-2-oxoethyl]-1,4,7,10tetraazacyclododecane-1,4,7-triyl]triacetate (25). Compound 25 was synthesized from 7 and 20 according to general procedure $\mathrm{D}$. Column chromatography $\left(\mathrm{SiO}_{2}, \mathrm{CHCl}_{3} / \mathrm{MeOH} 95: 5\right)$ furnished compound 25 (75\%); m.p. $142-146^{\circ} \mathrm{C} ;[\alpha]_{\mathrm{D}}=+20.5^{\circ}\left(\mathrm{c} 0.390, \mathrm{CHCl}_{3}\right) ; \mathrm{R}_{\mathrm{f}}=0.36\left(\mathrm{CHCl}_{3} / \mathrm{MeOH}\right.$ 9:1); IR (ATR): $v=2945 w, 2832 w, 1732 s, 1663 m, 1519 w, 1454 m, 1370 m, 1305 m, 1245 s, 1194 s, 1176 s$, 1105s, 1007m, 965m, 747m, 697s cm ${ }^{-1}$; UV-Vis $\left(\mathrm{CHCl}_{3}\right): \lambda_{\max }(\log \varepsilon)=241 \mathrm{~nm}(3.89), 295 \mathrm{~nm}(3.29)$, $364 \mathrm{~nm}(3.08) ;{ }^{1} \mathrm{H}$ NMR $\left(400 \mathrm{MHz}, \mathrm{CDCl}_{3}\right): \delta=8.20(t, J=4.5 \mathrm{~Hz}, 1 \mathrm{H}, \mathrm{NH}), 7.39-7.27(m, 15 \mathrm{H}, \mathrm{CH}$ $(\mathrm{Bn})), 7.01(t, J=4.9 \mathrm{~Hz}, 1 \mathrm{H}, \mathrm{NH}), 5.48(\mathrm{~s}, 1 \mathrm{H}, 12-\mathrm{H}), 5.26-5.05\left(m, 6 \mathrm{H}, \mathrm{CH}_{2}(\mathrm{Bn})\right), 4.47(d d, J=10.0$, $5.7 \mathrm{~Hz}, 1 \mathrm{H}, 3-\mathrm{H}), 3.77-2.07\left(\mathrm{~m}, 28 \mathrm{H}, 31-\mathrm{H}_{\mathrm{a}}, 31-\mathrm{H}_{\mathrm{b}}, 32-\mathrm{H}, 34-\mathrm{H}, 3 \times \mathrm{CH}_{2}\right.$ (acetate), $8 \times \mathrm{CH}_{2}$ (cyclen)), $2.41(d, J=10.7 \mathrm{~Hz}, 1 \mathrm{H}, 18-\mathrm{H}), 2.02(s, 3 \mathrm{H}, \mathrm{Ac}), 2.00-1.64\left(m, 6 \mathrm{H}, 16-\mathrm{H}_{\mathrm{a}}, 16-\mathrm{H}_{\mathrm{b}}, 11-\mathrm{H}_{\mathrm{a}}, 11-\mathrm{H}_{\mathrm{b}}, 22-\mathrm{H}_{\mathrm{a}}\right.$, $\left.15-\mathrm{H}_{\mathrm{a}}\right), 1.64-1.19\left(m, 12 \mathrm{H}, 1-\mathrm{H}_{\mathrm{a}}, 2-\mathrm{H}_{\mathrm{a}}, 2-\mathrm{H}_{\mathrm{b}}, 22-\mathrm{H}_{\mathrm{b}}, 9-\mathrm{H}, 6-\mathrm{H}_{\mathrm{a}}, 7-\mathrm{H}_{\mathrm{a}}, 21-\mathrm{H}_{\mathrm{a}}, 6-\mathrm{H}_{\mathrm{b}}, 19-\mathrm{H}, 21-\mathrm{H}_{\mathrm{b}}, 7-\mathrm{H}_{\mathrm{b}}\right)$, 1.17-0.97 ( $\left.m, 3 \mathrm{H}, 20-\mathrm{H}, 1-\mathrm{H}_{\mathrm{b}}, 15-\mathrm{H}_{\mathrm{b}}\right), 1.04(s, 3 \mathrm{H}, 27-\mathrm{H}), 0.89(d, J=6.3 \mathrm{~Hz}, 6 \mathrm{H}, 29-\mathrm{H}, 30-\mathrm{H}), 0.87(s, 3 \mathrm{H}$, 25-H), $0.83(s, 3 \mathrm{H}, 23-\mathrm{H}), 0.81(\mathrm{~s}, 3 \mathrm{H}, 24-\mathrm{H}), 0.80-0.76(\mathrm{~m}, 1 \mathrm{H}, 5-\mathrm{H}), 0.72(\mathrm{~s}, 3 \mathrm{H}, 26-\mathrm{H}) \mathrm{ppm} ;{ }^{13} \mathrm{C}$ NMR $\left(101 \mathrm{MHz}, \mathrm{CDCl}_{3}\right): \delta=178.8$ (C-28), 173.2 (CO, acetate), 172.0 (C-33), 171.0 (Ac), 139.0 (C-13), 135.4 $\left(\mathrm{C}_{\mathrm{i}}, \mathrm{Bn}\right), 135.4\left(\mathrm{C}_{\mathrm{i}}, \mathrm{Bn}\right), 135.3\left(\mathrm{C}_{\mathrm{i}}, \mathrm{Bn}\right), 128.8(\mathrm{CH}, \mathrm{Bn}), 128.8(\mathrm{CH}, \mathrm{Bn}), 128.7(\mathrm{CH}, \mathrm{Bn}), 128.6(\mathrm{CH}, \mathrm{Bn})$, 125.6 (12-H), $81.0(3-\mathrm{H}), 67.3\left(\mathrm{CH}_{2}, \mathrm{Bn}\right), 67.3\left(\mathrm{CH}_{2}, \mathrm{Bn}\right), 67.2\left(\mathrm{CH}_{2}, \mathrm{Bn}\right), 56.8\left(\mathrm{CH}_{2}\right.$, acetate), $55.4(\mathrm{C}-34)$, 55.3 (C-5), $55.3\left(\mathrm{CH}_{2}\right.$, cyclen), 52.3 (C-18), 47.7 (C-17), 47.6 (C-9), 42.2 (C-14), 40.1 (C-32), 39.8 (C-19), 39.7 (C-8), 38.5 (C-20), 38.5 (C-31, C-1), 37.8 (C-4), 37.4 (C-22), 37.0 (C-10), 32.9 (C-7), 31.2 (C-21), 28.2 (C-23), 28.0 (C-15), 24.5 (C-16), 23.7 (C-2), 23.5 (C-27), 23.4 (C-11), 21.4 (Ac), 21.4 (C-30), 18.4 (C-6), 17.2 (C-29), 17.1 (C-26), 16.8 (C-24), 15.6 (C-25) ppm; MS (ESI, MeOH): $m / z=1219.8\left(100 \%,[\mathrm{M}+\mathrm{Na}]^{+}\right)$; analysis calcd for $\mathrm{C}_{71} \mathrm{H}_{100} \mathrm{~N}_{6} \mathrm{O}_{10}$ (1197.61): C 71.21, $\mathrm{H}$ 8.42, N 7.02; found: 70.93, H 8.56, $\mathrm{N}$ 6.82.

Tri-tert-butyl 2,2',2"-[10-[2-[2-[2-(3ß-acetyloxy-urs-12-en-28-oylamino)ethoxy]ethyl]amino-2-oxoethyl]-1,4,7,10tetraazacyclododecane-1,4,7-triyl]triacetate (26). Compound $\mathbf{2 6}$ was synthesized from $\mathbf{6}$ and $\mathbf{2 1}$ according to general procedure $\mathrm{D}$. Column chromatography $\left(\mathrm{SiO}_{2}, \mathrm{CHCl}_{3} / \mathrm{MeOH} 95: 5\right)$ furnished compound 26 (74\%); m.p. $263-266^{\circ} \mathrm{C}$ (decomp.); $[\alpha]_{\mathrm{D}}=+21.9^{\circ}$ (c 0.315, $\left.\mathrm{CHCl}_{3}\right) ; \mathrm{R}_{\mathrm{f}}=0.38\left(\mathrm{CHCl}_{3} / \mathrm{MeOH} 9: 1\right) ; \mathrm{IR}$ (ATR): $v=2972 m, 2930 m, 1726 s, 1166 m, 1523 w, 1453 m, 1368 s, 1307 m, 1228 s, 1160 s, 1106 s, 1026 m, 1006 m$, $975 m, 755 \mathrm{~cm}^{-1} ;{ }^{1} \mathrm{H}$ NMR $\left(400 \mathrm{MHz}, \mathrm{CDCl}_{3}\right): \delta=7.82(t, J=5.6 \mathrm{~Hz}, 1 \mathrm{H}, \mathrm{NH}), 6.46(t, J=5.1 \mathrm{~Hz}$, $1 \mathrm{H}, \mathrm{NH}), 5.33(t, J=3.7 \mathrm{~Hz}, 1 \mathrm{H}, 12-\mathrm{H}), 4.47(d d, J=10.2,5.9 \mathrm{~Hz}, 1 \mathrm{H}, 3-\mathrm{H}), 3.56-3.30(m, 9 \mathrm{H}, 32-\mathrm{H}$, $\left.31-\mathrm{H}_{\mathrm{a}}, 33-\mathrm{H}, 36-\mathrm{H}, 34-\mathrm{H}\right), 3.28-3.16\left(m, 1 \mathrm{H}, 31-\mathrm{H}_{\mathrm{b}}\right), 3.15-2.05\left(\mathrm{~m}, 22 \mathrm{H}, 3 \times \mathrm{CH}_{2}\right.$ (acetate), $8 \times \mathrm{CH}_{2}$ (cyclen)), $2.02(\mathrm{~s}, 3 \mathrm{H}, \mathrm{Ac}), 2.02-1.21\left(\mathrm{~m}, 19 \mathrm{H}, 18-\mathrm{H}, 16-\mathrm{H}_{\mathrm{a}}, 11-\mathrm{H}_{\mathrm{a}}, 11-\mathrm{H}_{\mathrm{b}}, 22-\mathrm{H}_{\mathrm{b}}, 16-\mathrm{H}_{\mathrm{b}}, 15-\mathrm{H}_{\mathrm{a}}, 1-\mathrm{H}_{\mathrm{a}}\right.$, $\left.2-\mathrm{H}_{\mathrm{a}}, 2-\mathrm{H}_{\mathrm{b}}, 9-\mathrm{H}, 6-\mathrm{H}_{\mathrm{a}}, 21-\mathrm{H}_{\mathrm{a}}, 7-\mathrm{H}_{\mathrm{a}}, 22-\mathrm{H}_{\mathrm{b}}, 19-\mathrm{H}, 6-\mathrm{H}_{\mathrm{b}}, 21-\mathrm{H}_{\mathrm{b}}, 7-\mathrm{H}_{\mathrm{b}}\right), 1.44\left(s, 9 \mathrm{H}, \mathrm{CH}_{3}(t\right.$ Butyl)), 1.43 $\left(s, 18 \mathrm{H}, \mathrm{CH}_{3}\right.$ (tButyl)), 1.06 (s, 3H, 27-H), 1.05-0.94 (m, 3H, 1- $\left.\mathrm{H}_{\mathrm{b}}, 15-\mathrm{H}_{\mathrm{b}}, 20-\mathrm{H}\right), 0.92(s, 3 \mathrm{H}, 25-\mathrm{H}), 0.92$ $(d, J=6.2 \mathrm{~Hz}, 3 \mathrm{H}, 30-\mathrm{H}), 0.86(d, J=6.5 \mathrm{~Hz}, 3 \mathrm{H}, 29-\mathrm{H}), 0.84(\mathrm{~s}, 3 \mathrm{H}, 23-\mathrm{H}), 0.83(\mathrm{~s}, 3 \mathrm{H}, 24-\mathrm{H}), 0.82-0.77$ $(m, 1 \mathrm{H}, 5-\mathrm{H}), 0.76(\mathrm{~s}, 3 \mathrm{H}, 26-\mathrm{H}) \mathrm{ppm} ;{ }^{13} \mathrm{C}$ NMR $\left(101 \mathrm{MHz}, \mathrm{CDCl}_{3}\right): \delta=178.3$ (C-28), 173.0 (CO, acetate), 172.5 (CO, acetate), 172.1 (C-35), 171.1 (Ac), 139.3 (C-13), 125.7 (C-12), 82.1 (C $\mathrm{C}_{\mathrm{q}}$, tButyl), 82.0 (C $\mathrm{C}_{\mathrm{q}}$, tButyl), 81.9 ( $\mathrm{C}_{\mathrm{q}}$, tButyl), 81.0 (C-3), 69.5 (C-33), 69.0 (C-32), 56.5 (C-36), $55.9\left(\mathrm{CH}_{2}\right.$, acetate), $55.8\left(\mathrm{CH}_{2}\right.$, acetate), $55.7\left(\mathrm{CH}_{2}\right.$, cyclen), 55.4 (C-5), 53.4 (C-18), 47.8 (C-17), 47.6 (C-9), 42.4 (C-14), 39.8 (C-19), 39.7 (C-8), 39.2 (C-31), 39.0 (C-34), 39.0 (C-20), 38.4 (C-1), 37.8 (C-4), 37.3 (C-22), 37.0 (C-10), 32.9 (C-7), 31.1 (C-21), 28.2 ( $\mathrm{CH}_{3}$, tButyl), $28.0\left(\mathrm{CH}_{3}, t\right.$ Butyl), 28.0 (C-23), 28.0 (C-15), 24.9 (C-16), 23.7 (C-2), 23.5 (C-11), 23.4 (C-27), 21.4 (Ac), 21.4 (C-30), 18.3 (C-6), 17.3 (C-29), 17.0 (C-26), 16.8 (C-24), 15.7 (C-25) ppm; MS (ESI, MeOH): $m / z=1161.7\left(100 \%,[\mathrm{M}+\mathrm{Na}]^{+}\right)$; analysis calcd for $\mathrm{C}_{64} \mathrm{H}_{110} \mathrm{~N}_{6} \mathrm{O}_{11}$ (1139.6): C 67.45, H 9.73, N 7.37; found: C 67.31, H 9.87, N 7.09.

Tribenzyl 2,2',2"-[10-[2-[2-[2-(3ß-acetyloxy-urs-12-en-28-oylamino)ethoxy]ethyl]amino-2-oxoethyl]-1,4,7,10tetraazacyclododecane-1,4,7-triyl]triacetate (27). Compound 27 has been synthesized from 7 and 21 according to general procedure D. Column chromatography $\left(\mathrm{SiO}_{2}, \mathrm{CHCl}_{3} / \mathrm{MeOH}\right.$ 95:5) furnished compound $27(62 \%)$; m.p. $137-141^{\circ} \mathrm{C} ;[\alpha]_{\mathrm{D}}=+15.4^{\circ}\left(\mathrm{c} 0.350, \mathrm{CHCl}_{3}\right) ; \mathrm{R}_{\mathrm{f}}=0.35\left(\mathrm{CHCl}_{3} / \mathrm{MeOH} 9: 1\right)$; IR (ATR): $v=2945 w, 2830 w, 1731 s, 1662 m, 1523 w, 1454 m, 1390 m, 1370 m, 1305 m, 1245 s, 1193 s, 1105 s$, 
$1026 \mathrm{~m}, 1008 \mathrm{~m}, 967 \mathrm{~m}, 747 \mathrm{~m}, 697 \mathrm{~m} \mathrm{~cm}^{-1}$; UV-Vis $\left(\mathrm{CHCl}_{3}\right): \lambda_{\max }(\log \varepsilon)=244 \mathrm{~nm}(3.73), 294 \mathrm{~nm}$ (3.36), $363 \mathrm{~nm}(3.12) ;{ }^{1} \mathrm{H}$ NMR $\left(400 \mathrm{MHz}, \mathrm{CDCl}_{3}\right): \delta=8.02(t, J=5.4 \mathrm{~Hz}, 1 \mathrm{H}, \mathrm{NH}), 7.37-7.27(m, 15 \mathrm{H}, \mathrm{CH}$ $(\mathrm{Bn})), 6.48(t, J=5.1 \mathrm{~Hz}, 1 \mathrm{H}, \mathrm{NH}), 5.32(t, J=3.5 \mathrm{~Hz}, 1 \mathrm{H}, 12-\mathrm{H}), 5.24-5.14\left(m, 4 \mathrm{H}, \mathrm{CH}_{2}(\mathrm{Bn})\right), 5.14-5.05$ $\left(m, 2 \mathrm{H}, \mathrm{CH}_{2}(\mathrm{Bn})\right), 4.46(d d, J=10.2,5.7 \mathrm{~Hz}, 1 \mathrm{H}, 3-\mathrm{H}), 3.59-3.33\left(m, 9 \mathrm{H}, 32-\mathrm{H}, 33-\mathrm{H}, 31-\mathrm{H}_{\mathrm{a}}, 34-\mathrm{H}, 36-\mathrm{H}\right)$, 3.33-2.01 (m, 23H, 31- $\mathrm{H}_{\mathrm{b}}, 8 \times \mathrm{CH}_{2}$ (cyclen), $3 \times \mathrm{CH}_{2}$ (acetate)), $2.02(\mathrm{~s}, 3 \mathrm{H}, \mathrm{Ac}), 2.00-1.17(\mathrm{~m}, 19 \mathrm{H}$, 18-H, 16- $\mathrm{H}_{\mathrm{a}}, 11-\mathrm{H}_{\mathrm{a}}, 11-\mathrm{H}_{\mathrm{b}}, 22-\mathrm{H}_{\mathrm{a}}, 16-\mathrm{H}_{\mathrm{b}}, 15-\mathrm{H}_{\mathrm{a}}, 1-\mathrm{H}_{\mathrm{a}}, 2-\mathrm{H}_{\mathrm{a}}, 2-\mathrm{H}_{\mathrm{b}}, 9-\mathrm{H}, 6-\mathrm{H}_{\mathrm{a}}, 22-\mathrm{H}_{\mathrm{b}}, 7-\mathrm{H}_{\mathrm{a}}, 21-\mathrm{H}_{\mathrm{a}}, 19-\mathrm{H}$, 6- $\left.\mathrm{H}_{\mathrm{b}}, 7-\mathrm{H}_{\mathrm{b}}, 21-\mathrm{H}_{\mathrm{b}}\right), 1.05(\mathrm{~s}, 3 \mathrm{H}, 27-\mathrm{H}), 1.04-0.94\left(\mathrm{~m}, 3 \mathrm{H}, 1-\mathrm{H}_{\mathrm{b}}, 15-\mathrm{H}_{\mathrm{b}}, 20-\mathrm{H}\right), 0.90(\mathrm{~s}, 3 \mathrm{H}, 25-\mathrm{H}), 0.90$ $(d, J=5.8 \mathrm{~Hz}, 3 \mathrm{H}, 30-\mathrm{H}), 0.85(d, J=6.6 \mathrm{~Hz}, 3 \mathrm{H}, 29-\mathrm{H}), 0.84(s, 3 \mathrm{H}, 23-\mathrm{H}), 0.82(s, 3 \mathrm{H}, 24-\mathrm{H}), 0.81-0.76$ $(m, 1 \mathrm{H}, 5-\mathrm{H}), 0.75(\mathrm{~s}, 3 \mathrm{H}, 26-\mathrm{H}) \mathrm{ppm} ;{ }^{13} \mathrm{C} \mathrm{NMR}\left(101 \mathrm{MHz}, \mathrm{CDCl}_{3}\right): \delta=178.3(\mathrm{C}-28), 173.3$ (CO, acetate), 173.1 (CO, acetate), 172.3 (C-35), 171.1 (Ac), 139.3 (C-13), $135.4\left(\mathrm{C}_{\mathrm{i}}, \mathrm{Bn}\right), 135.3\left(\mathrm{C}_{\mathrm{i}}, \mathrm{Bn}\right), 128.7(\mathrm{CH}, \mathrm{Bn})$, 128.7 (CH, Bn), 128.7 (CH, Bn), 128.6 (CH, Bn), 128.5 (CH, Bn), 125.7 (C-12), 81.0 (C-3), 69.6 (C-33), 68.9 (C-32), $67.2\left(\mathrm{CH}_{2}, \mathrm{Bn}\right), 67.2\left(\mathrm{CH}_{2}, \mathrm{Bn}\right), 56.9(\mathrm{C}-36), 55.4\left(3 \times \mathrm{CH}_{2}\right.$, acetate), $55.4(\mathrm{C}-5), 55.3\left(8 \times \mathrm{CH}_{2}\right.$, cyclen), 53.3 (C-18), 47.8 (C-17), 47.6 (C-9), 42.4 (C-14), 39.8 (C-19), 39.7 (C-8), 39.2 (C-31, C-34), 38.9 (C-20), 38.4 (C-1), 37.8 (C-4), 37.3 (C-22), 36.9 (C-10), 32.9 (C-7), 31.1 (C-21), 28.2 (C-23), 28.0 (C-15), 24.8 (C-16), 23.6 (C-2), 23.5 (C-11), 23.4 (C-27), 21.4 (Ac), 21.4 (C-30), 18.3 (C-6), 17.3 (C-29), 17.1 (C-26), 16.8 (C-24), 15.7 (C-25) ppm; MS (ESI, MeOH): $m / z=1263.9\left(100 \%\right.$, $\left.[\mathrm{M}+\mathrm{Na}]^{+}\right)$; analysis calcd for $\mathrm{C}_{73} \mathrm{H}_{104} \mathrm{~N}_{6} \mathrm{O}_{11}$ (1241.67): C 70.62, H 8.44, N 6.77; found: C 70.41, H 8.69, N 6.41.

(3ß) N-(2-Aminoethyl)-3-hydroxy-urs-12-en-28-amide (28). Method A: The synthesis was performed according to the procedure given in the Supplementary material in $82 \%$. Method B: Ursolic acid $(100 \mathrm{mg}$, $0.20 \mathrm{mmol}), \mathrm{HOBt} \cdot \mathrm{H}_{2} \mathrm{O}(37 \mathrm{mg}, 0.24 \mathrm{mmol})$ and $\mathrm{EDC} \cdot \mathrm{HCl}(46 \mathrm{mg}, 0.24 \mathrm{mmol})$ were dissolved in dry DMF $(5 \mathrm{~mL})$, and the mixture was stirred for $30 \mathrm{~min}$ at $25^{\circ} \mathrm{C}$. Ethylene diamine $(55 \mu \mathrm{L}, 0.82 \mathrm{mmol})$ was added to the mixture, and stirring was continued for $24 \mathrm{~h}$ at $25^{\circ} \mathrm{C}$. Usual aqueous work-up followed by column chromatography (silica gel, $\mathrm{CHCl}_{3} / \mathrm{MeOH} / \mathrm{NH}_{4} \mathrm{OH}$ 90:10:0.1) gave 28 (46\%). Analytical data of this compound can be found in the supplementary material.

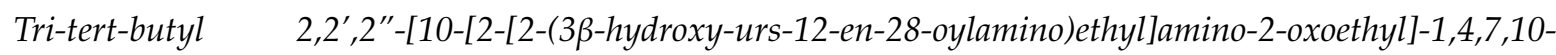
tetraazacyclododecane-1,4,7-triyl]triacetate (29). Method A: To a solution of DOTA-tris(tert-butyl ester) $(58 \mathrm{mg}, 0.10 \mathrm{mmol})$ in dry DMF $(8 \mathrm{~mL})$ were added $\mathrm{HOBt} \cdot \mathrm{H}_{2} \mathrm{O}(29 \mathrm{mg}, 0.19 \mathrm{mmol})$ and EDC.HCl $(29 \mathrm{mg}, 0.15 \mathrm{mmol})$. After stirring for $30 \mathrm{~min}$ at $25^{\circ} \mathrm{C}$, a solution of $28(71 \mathrm{mg}, 0.14 \mathrm{mmol})$ in dry DMF $(2 \mathrm{~mL})$ was added and stirring was continued for 5 days. After usual aqueous work-up, the solvent was removed under reduced pressure and the crude product was subjected to column chromatography (silica gel, $\mathrm{CHCl}_{3} / \mathrm{MeOH}$ 9:1) yielding compound 29 as colorless solid. Yield: 49\%. Method B: Compound $24(50 \mathrm{mg}, 0.10 \mathrm{mmol})$ was dissolved in methanol $(7 \mathrm{~mL})$ and a solution of potassium hydroxide $(12 \mathrm{mg}, 0.21 \mathrm{mmol})$ in methanol $(1 \mathrm{~mL})$ was added. The mixture was stirred at $25^{\circ} \mathrm{C}$ for $24 \mathrm{~h}$. After completion of the reaction (as indicated by TLC) and usual work-up, the solvent was removed under reduced pressure, and the residue was subjected to column chromatography (silica gel, $\mathrm{CHCl}_{3} / \mathrm{MeOH} 9: 1$ ) affording 29 (yield: 86\%); m.p. $136-139^{\circ} \mathrm{C} ;[\alpha]_{\mathrm{D}}=-44.4^{\circ}$ (c 0.330, MeOH); $\mathrm{R}_{\mathrm{f}}=0.29$ $\left(\mathrm{CHCl}_{3} / \mathrm{MeOH} 9: 1\right)$; IR (KBr): $v=3300 b r w, 2973 w, 2928 m, 2869 w, 1728 s, 1668 m, 1525 m, 1455 m, 1425 w$, $1368 \mathrm{~s}, 1307 \mathrm{~m}, 1227 \mathrm{~s}, 1159 \mathrm{~s}, 1121 \mathrm{~m}, 1106 \mathrm{~s}, 1047 w, 1006 w \mathrm{~cm}^{-1} ;{ }^{1} \mathrm{H}$ NMR $\left(400 \mathrm{MHz}, \mathrm{CDCl}_{3}\right): \delta=8.84$ $(s, 1 \mathrm{H}, \mathrm{NH}), 7.55(s, 1 \mathrm{H}, \mathrm{NH}), 5.36(t, J=3.5 \mathrm{~Hz}, 1 \mathrm{H}, 12-\mathrm{H}), 3.59-2.05(m, 28 \mathrm{H}, 31-\mathrm{H}, 32-\mathrm{H}, 33-\mathrm{H}$, $3 \times \mathrm{CH}_{2}$ (acetate), $8 \times \mathrm{CH}_{2}$ (cyclen)), $3.20(d d, J=11.1,4.8 \mathrm{~Hz}, 1 \mathrm{H}, 3-\mathrm{H}), 2.34(d, J=11.0 \mathrm{~Hz}, 2 \mathrm{H}, 18-\mathrm{H})$, 2.03-1.96 $\left(m, 1 \mathrm{H}, 16-\mathrm{H}_{\mathrm{a}}\right), 1.95-1.83\left(m, 3 \mathrm{H}, 11-\mathrm{H}_{\mathrm{a}}, 11-\mathrm{H}_{\mathrm{b}}, 16-\mathrm{H}_{\mathrm{b}}\right), 1.83-1.72\left(m, 1 \mathrm{H}, 22-\mathrm{H}_{\mathrm{a}}\right), 1.64-1.21$ $\left(m, 13 \mathrm{H}, 1-\mathrm{H}_{\mathrm{a}}, 15-\mathrm{H}_{\mathrm{a}}, 2-\mathrm{H}_{\mathrm{a}}, 2-\mathrm{H}_{\mathrm{b}}, 22-\mathrm{H}_{\mathrm{b}}, 6-\mathrm{H}_{\mathrm{a}}, 9-\mathrm{H}, 7-\mathrm{H}_{\mathrm{a}}, 21-\mathrm{H}_{\mathrm{a}}, 19-\mathrm{H}, 6-\mathrm{H}_{\mathrm{b}}, 7-\mathrm{H}_{\mathrm{b}}, 21-\mathrm{H}_{\mathrm{b}}\right), 1.45(s, 9 \mathrm{H}$, $\mathrm{CH}_{3}$ (tButyl)), $1.43\left(\mathrm{~s}, 18 \mathrm{H}, \mathrm{CH}_{3}\right.$ (tButyl)), $1.05(\mathrm{~s}, 3 \mathrm{H}, 27-\mathrm{H}), 1.04-0.97\left(m, 3 \mathrm{H}, 1-\mathrm{H}_{\mathrm{b}}, 15-\mathrm{H}_{\mathrm{b}}, 20-\mathrm{H}\right), 0.97$ $(s, 3 \mathrm{H}, 23-\mathrm{H}), 0.89(d, J=6.3 \mathrm{~Hz}, 3 \mathrm{H}, 30-\mathrm{H}), 0.89(s, 3 \mathrm{H}, 25-\mathrm{H}), 0.85(d, J=6.4 \mathrm{~Hz}, 3 \mathrm{H}, 29-\mathrm{H}), 0.76(s, 3 \mathrm{H}$, 24-H), 0.75 (s, 3H, 26-H), 0.72-0.68 ( $\left.m, 1 \mathrm{H}, 5-\mathrm{H}) \mathrm{ppm} ;{ }^{13} \mathrm{C} \mathrm{NMR} \mathrm{(101} \mathrm{MHz,} \mathrm{CDCl}_{3}\right): \delta=178.4(\mathrm{C}-28)$, 172.4 (CO, acetate), 171.8 (C-33), 138.9 (C-13), 125.3 (C-12), $82.2\left(\mathrm{C}_{\mathrm{q}}\right.$, tButyl), $82.1\left(\mathrm{C}_{\mathrm{q}}\right.$, tButyl), $82.1\left(\mathrm{C}_{\mathrm{q}}\right.$, tButyl), 79.2 (C-3), $56.0\left(\mathrm{CH}_{2}\right.$, acetate), 55.9 (C-34), $55.8\left(\mathrm{CH}_{2}\right.$, cyclen), 55.3 (C-5), 52.5 (C-18), 47.8 (C-9), 47.5 (C-17), 42.2 (C-14), 40.0 (C-32), 39.7 (C-8), 39.6 (C-19), 38.9 (C-4), 38.7 (C-20), 38.7 (C-31, C-1), 37.4 (C-22), 37.1 (C-10), 33.2 (C-7), 31.3 (C-21), 28.3 (C-23), $28.2\left(\mathrm{CH}_{3}\right.$, tButyl), $28.2\left(\mathrm{CH}_{3}\right.$, tButyl), $28.1\left(\mathrm{CH}_{3}\right.$, 
tButyl), 28.0 (C-15), 27.4 (C-2), 24.2 (C-16), 23.6 (C-27), 23.5 (C-11), 21.5 (C-30), 18.6 (C-6), 17.2 (C-29), 17.1 (C-26), 15.8 (C-24), 15.7 (C-25) ppm; MS (ESI, MeOH): $\mathrm{m} / z=1075.7\left(100 \%,[\mathrm{M}+\mathrm{Na}]^{+}\right)$; analysis calcd for $\mathrm{C}_{60} \mathrm{H}_{104} \mathrm{~N}_{6} \mathrm{O}_{9}$ (1053.53): C 68.40, H 9.95, N 7.98; found: C 60.09, H 10.11, N 7.83.

Supplementary Materials: Supplementary data related to this article including experimental procedures for compounds 10, 17, 18, and 28, Figure S1: Extended cytotoxicity investigation after treatment of A375 cells with 22 $(3.0 \mu \mathrm{M})$ for $24 \mathrm{~h}$, representative NMR spectra and calculation of ADMET parameters for compounds 22 and 24 can be found online.

Author Contributions: M.K.; and R.C. conceived and designed the experiments; M.K. performed the experiments; S.H. and L.F. performed the biological assays and experiments; M.K.; A.A-H.; and R.C. analyzed the data and wrote the paper.

Funding: We acknowledge the financial support within the funding program Open Access Publishing by the German Research Foundation (DFG).

Acknowledgments: We would like to thank R. Kluge for measuring the ESI-MS spectra and D. Ströhl and his team for the NMR spectra. Thanks are also due to V. Simon for measuring the IR an UV-VIS spectra and optical rotations. The cell lines were kindly provided by Th. Müller (Dept. of Haematology/Oncology, Martin-Luther Universität Halle-Wittenberg).

Conflicts of Interest: The authors declare no conflict of interest.

\section{References}

1. Bray, F.; Ferlay, J.; Soerjomataram, I.; Siegel, R.L.; Torre, L.A.; Jemal, A. Global cancer statistics 2018: GLOBOCAN estimates of incidence and mortality worldwide for 36 cancers in 185 countries. Ca-Cancer J. Clin. 2018, 68, 394-424. [CrossRef] [PubMed]

2. Stasiuk, G.J.; Long, N.J. The ubiquitous DOTA and its derivatives: The impact of 1, 4, 7, 10-tetraazacyclododecane-1, 4, 7, 10-tetraacetic acid on biomedical imaging. Chem. Commun. 2013, 49, 2732-2746. [CrossRef] [PubMed]

3. Chilla, S.N.M.; Henoumont, C.; Elst, L.V.; Muller, R.N.; Laurent, S. Importance of DOTA derivatives in bimodal imaging. Isr. J. Chem. 2017, 57, 800-808. [CrossRef]

4. Magerstädt, M.; Gansow, O.A.; Brechbiel, M.W.; Colcher, D.; Baltzer, L.; Knop, R.H.; Girton, M.E.; Naegele, M. Gd (DOTA): An alternative to Gd (DTPA) as a T1, 2 relaxation agent for NMR imaging or spectroscopy. Magn. Reson. Med. 1986, 3, 808-812. [CrossRef] [PubMed]

5. Jones-Wilson, T.M.; Deal, K.A.; Anderson, C.J.; McCarthy, D.W.; Kovacs, Z.; Motekaitis, R.J.; Sherry, A.D.; Martell, A.E.; Welch, M.J. The in vivo behavior of copper-64-labeled azamacrocyclic complexes. Nucl. Med. Biol. 1998, 25, 523-530. [CrossRef]

6. Wu, A.M.; Yazaki, P.J.; Tsai, S.-w.; Nguyen, K.; Anderson, A.-L.; McCarthy, D.W.; Welch, M.J.; Shively, J.E.; Williams, L.E.; Raubitschek, A.A. High-resolution microPET imaging of carcinoembryonic antigen-positive xenografts by using a copper-64-labeled engineered antibody fragment. Proc. Natl. Acad. Sci. USA 2000, 97, 8495-8500. [CrossRef] [PubMed]

7. Deshpande, S.V.; DeNardo, S.J.; Kukis, D.L.; Moi, M.K.; McCall, M.J.; DeNardo, G.L.; Meares, C.F. Yttrium-90-labeled monoclonal antibody for therapy: Labeling by a new macrocyclic bifunctional chelating agent. J. Nucl. Med. 1990, 31, 473-479.

8. Razboršek, M.I.; Vončina, D.B.; Doleček, V.; Vončina, E. Determination of Oleanolic, Betulinic and Ursolic Acid in Lamiaceae and Mass Spectral Fragmentation of Their Trimethylsilylated Derivatives. Chromatographia 2008, 67, 433-440. [CrossRef]

9. Fu, L.; Zhang, S.; Li, N.; Wang, J.; Zhao, M.; Sakai, J.; Hasegawa, T.; Mitsui, T.; Kataoka, T.; Oka, S.; et al. Three New Triterpenes from Nerium oleander and Biological Activity of the Isolated Compounds. J. Nat. Prod. 2005, 68, 198-206. [CrossRef]

10. Cargnin, S.T.; Gnoatto, S.B. Ursolic acid from apple pomace and traditional plants: A valuable triterpenoid with functional properties. Food Chem. 2017, 220, 477-489. [CrossRef]

11. Yamaguchi, H.; Noshita, T.; Kidachi, Y.; Umetsu, H.; Hayashi, M.; Komiyama, K.; Funayama, S.; Ryoyama, K. Isolation of Ursolic Acid from Apple Peels and Its Specific Efficacy as a Potent Antitumor Agent. J. Health Sci. 2008, 54, 654-660. [CrossRef] 
12. Chen, H.; Gao, Y.; Wang, A.; Zhou, X.; Zheng, Y.; Zhou, J. Evolution in medicinal chemistry of ursolic acid derivatives as anticancer agents. Eur. J. Med. Chem. 2015, 92, 648-655. [CrossRef] [PubMed]

13. Hussain, H.; Green, I.R.; Ali, I.; Khan, I.A.; Ali, Z.; Al-Sadi, A.M.; Ahmed, I. Ursolic acid derivatives for pharmaceutical use: A patent review (2012-2016). Expert Opin. Pat. 2017, 27, 1061-1072. [CrossRef] [PubMed]

14. Seo, D.Y.; Lee, S.R.; Heo, J.-W.; No, M.-H.; Rhee, B.D.; Ko, K.S.; Kwak, H.-B.; Han, J. Ursolic acid in health and disease. Korean J. Physiol. Pharm. 2018, 22, 235-248. [CrossRef] [PubMed]

15. Zou, J.; Lin, J.; Li, C.; Zhao, R.; Fan, L.; Yu, J.; Shao, J. Ursolic Acid in Cancer Treatment and Metastatic Chemoprevention: From Synthesized Derivatives to Nanoformulations in Preclinical Studies. Curr. Cancer Drug Targets 2019, 19, 245-256. [CrossRef] [PubMed]

16. Ma, C.-M.; Cai, S.-Q.; Cui, J.-R.; Wang, R.-Q.; Tu, P.-F.; Hattori, M.; Daneshtalab, M. The cytotoxic activity of ursolic acid derivatives. Eur. J. Med. Chem. 2005, 40, 582-589. [CrossRef] [PubMed]

17. Liu, D.; Meng, Y.-q.; Zhao, J.; Chen, L.-g. Synthesis and Anti-tumor Activity of Novel Amide Derivatives of Ursolic Acid. Chem. Res. Chin. Univ. 2008, 24, 42-46. [CrossRef]

18. Meng, Y.-Q.; Liu, D.; Cai, L.-L.; Chen, H.; Cao, B.; Wang, Y.-Z. The synthesis of ursolic acid derivatives with cytotoxic activity and the investigation of their preliminary mechanism of action. Bioorg. Med. Chem. 2009, 17, 848-854. [CrossRef]

19. Liu, M.-C.; Yang, S.-J.; Jin, L.-H.; Hu, D.-Y.; Xue, W.; Song, B.-A.; Yang, S. Synthesis and cytotoxicity of novel ursolic acid derivatives containing an acyl piperazine moiety. Eur. J. Med. Chem. 2012, 58, 128-135. [CrossRef]

20. Sommerwerk, S.; Heller, L.; Kerzig, C.; Kramell, A.E.; Csuk, R. Rhodamine B conjugates of triterpenoic acids are cytotoxic mitocans even at nanomolar concentrations. Eur. J. Med. Chem. 2017, 127, 1-9. [CrossRef]

21. Kahnt, M.; Fischer, L.; Al-Harrasi, A.; Csuk, R. Ethylenediamine Derived Carboxamides of Betulinic and Ursolic Acid as Potential Cytotoxic Agents. Molecules 2018, 23, 2558. [CrossRef] [PubMed]

22. Kim, S.-M.; Jeong, I.H.; Yim, M.S.; Chae, M.K.; Kim, H.N.; Kim, D.K.; Kang, C.M.; Choe, Y.S.; Lee, C.; Ryu, E.K. Characterization of oleanolic acid derivative for colon cancer targeting with positron emission tomography. J. Drug Target. 2014, 22, 191-199. [CrossRef] [PubMed]

23. Yang, X.; Li, Y.; Jiang, W.; Ou, M.; Chen, Y.; Xu, Y.; Wu, Q.; Zheng, Q.; Wu, F.; Wang, L. Synthesis and biological evaluation of novel ursolic acid derivatives as potential anticancer prodrugs. Chem. Biol. Drug Des. 2015, 86, 1397-1404. [CrossRef]

24. Bai, K.-K.; Yu, Z.; Chen, F.-L.; Li, F.; Li, W.-Y.; Guo, Y.-H. Synthesis and evaluation of ursolic acid derivatives as potent cytotoxic agents. Bioorg. Med. Chem. Lett. 2012, 22, 2488-2493. [CrossRef] [PubMed]

25. Rami, M.; Cecchi, A.; Montero, J.-L.; Innocenti, A.; Vullo, D.; Scozzafava, A.; Winum, J.-Y.; Supuran, C.T. Carbonic Anhydrase Inhibitors: Design of Membrane-Impermeant Copper(II) Complexes of DTPA-, DOTA-, and TETA-Tailed Sulfonamides Targeting the Tumor-Associated Transmembrane Isoform IX. ChemMedChem 2008, 3, 1780-1788. [CrossRef]

26. Loesche, A.; Kahnt, M.; Serbian, I.; Brandt, W.; Csuk, R. Triterpene-Based Carboxamides Act as Good Inhibitors of Butyrylcholinesterase. Molecules 2019, 24, 948. [CrossRef] [PubMed]

27. Deng, S.-L.; Baglin, I.; Nour, M.; Cavé, C. Synthesis of phosphonodipeptide conjugates of ursolic acid and their homologs. Heteroat. Chem. 2008, 19, 55-65. [CrossRef]

Sample Availability: Samples of all compounds are available from the authors. 